\title{
La teoría de la educación es disciplina y es herramienta necesaria para dominar la intervención pedagógica.
}

\section{The theory of education is discipline and is a necessary tool to master pedagogical intervention.}

\author{
José Manuel Touriñán López ${ }^{1 *}$ \\ 1 Facultad de Ciencias de la Educación, Departamento de Pedagogía y didáctica. Campus Vida s/n. 15782. Santiago de Compostela. \\ * Correspondencia: http://dondestalaeducacion.com/http://dondestalaeducacion.com/ \\ https://www.youtube.com/channel/UCzbNAzwFApNMViix5 HDz0w Researcher ID: \\ http://www.researcherid.com/rid/L-1032-2014 Orcid: http://orcid.org/0000-0002-7553-4483
}

Received: 01/01/2020; Accepted: 01/06/2020; Published: 03/07/2020

\section{Resumen:}

Una disciplina que tiene conceptos propios, autóctonos, puede aplicarse a la interpretación de otros ámbitos de realidad siempre que esos ámbitos se ajusten a esos conceptos originarios en alguna medida. De este modo la disciplina generadora se convierte en teoría interpretativa del ámbito en el que se aplica, porque lo interpreta desde los conceptos de la disciplina generadora. Desde esa misma perspectiva, los conceptos propios, autóctonos, de la disciplina pedagogía pueden utilizarse para generar disciplinas aplicadas como la pedagogía laboral, la pedagogía familiar, la pedagogía ambiental, la pedagogía social, la pedagogía carcelaria, etc. Lo importante es poder ir desde la Pedagogía General a las Pedagogías aplicadas, porque muy diversos ámbitos de realidad pueden ser interpretados como aplicaciones desde la disciplina Pedagogía. La pedagogía del futuro será necesariamente el reino de las pedagogías aplicadas. La pedagogía genera investigaciones aplicadas sobre otros ámbitos de realidad y conocimiento y otras disciplinas científicas generan investigación aplicada sobre el ámbito de conocimiento 'educación'. Respecto de la educación hay pluralidad de investigaciones teóricas; unas nacen desde la Pedagogía y otras nacen desde otras ciencias Hay investigaciones teóricas acerca de la educación y hay investigaciones de teoría práctica (ambas se construyen desde otras disciplinas científicas). También hay investigación teórica que nace de la disciplina científica 'pedagogía': hay investigaciones teóricas de la educación (teoría como nivel de análisis epistemológico) y hay investigaciones de Teoría de la educación como disciplina (disciplina de pedagogía general o disciplina de teoría de la educación, en sentido estricto). El objetivo de este artículo es comprender la relación entre 'teoría' y 'educación' por medio del conocimiento de la educación, su diversidad como disciplina y como investigación. Es posible realizar ese objetivo, porque la teoría de la educación es conocimiento de la educación; hay una relación entre teoría y educación por medio del conocimiento de la educación. Cada modo de entender el conocimiento de la educación, permite entender el significado de la teoría en relación con 'educación'. Es posible integrar las diversas posiciones que existen en la pluralidad semántica del concepto 'teoría' en relación con 'educación', bien como disciplina científica y materia curricular, bien como modo de investigación. Y si entendemos el alcance de la relación entre 'teoría' y 'educación', entenderemos el significado del título de este artículo: Teoría de la educación es una disciplina y es una herramienta necesaria para dominar la intervención pedagógica.

Palabras Claves: Pedagogía general, pedagogía aplicada, epistemología de la educación, pedagogía mesoaxiológica, conocimiento de la educación, teoría de la educación. 


\begin{abstract}
:
A discipline which has its own concepts, original ones, can be applied to the interpretation of other realms of reality as long as those realms can be adjusted to those original concepts to some extent. In this way the generative discipline becomes an interpretive theory of the field in which it is applied, because it interprets it from the concepts that the generative discipline has made. From this same perspective, the own concepts, autochthonous concepts, of the pedagogy discipline can be used to generate applied disciplines (interpretative theories) such as labor pedagogy, family pedagogy, environmental pedagogy, social pedagogy, prison pedagogy, etc. The important thing is to be able to go from General Pedagogy to applied Pedagogies, because very diverse spheres of knowledge can be interpreted as applications in terms of the Pedagogy discipline. The pedagogy of the future will necessarily be the realm of applied pedagogies. Pedagogy generates applied research on other fields of reality and knowledge and other scientific disciplines generate applied research on the field of knowledge 'education'. Regarding education there is a plurality of theoretical research; some are born from Pedagogy and others are born from other scientific disciplines. There is theoretical research about education and there is education practical theory research (both of two are built from other scientific disciplines). There is also theoretical research which has born from the discipline 'Pedagogy': there is theoretical research of education (theory as a level of epistemological analysis) and there is research of educational theory as a discipline (general pedagogy discipline or theory of education discipline, in strict sense). The objective of this article is to understand the relationship between 'theory' and 'education' by means of the knowledge of education, its diversity as a discipline and as research. It is possible to accomplish that objective, because the theory of education is knowledge of education; there is a relationship between theory and education through knowledge of education. Each way of understanding the knowledge of education allows us to understand the meaning of the theory in relation to 'education'. It is possible to integrate the diverse positions that exist in the semantic plurality of the concept of 'theory' in relation to 'education', either as a discipline and subject-matter of curriculum or as a way of research. And if we understand the scope of the relationship between 'theory' and 'education', we will understand the meaning of the title of this article: Theory of education is a discipline and it is a necessary tool to master pedagogical intervention.
\end{abstract}

Keywords: General pedagogy, applied pedagogy, epistemology of education, mesoaxiological pedagogy, knowledge of education, theory of education.

\title{
1. Introducción
}

En el entorno académico español distinguimos "Pedagogía" como carrera y como disciplina y "Educación" como actividad real y como disciplina de conocimiento de la educación. Podemos hablar de educación, no solo como actividad, sino también como disciplina, en el sentido de arte o ciencia y la educación es una de esas cosas o ambas, según de qué se esté hablando en cada caso (Touriñán, 2016).

Es posible hablar de la educación como disciplina, utilizando el todo por la parte, es decir, hablamos de educación como disciplina, tomando la educación por la parte que es Pedagogía (disciplina dedicada al conocimiento teórico, tecnológico y practico de la educación). Por otra parte, es posible decir que educación es disciplina, entendiendo educación como materia de estudio y análisis (conocimiento de educación). Así las cosas, en ambas posibilidades, tiene sentido decir que la educación es una actividad y un ámbito de realidad que se convierte en materia de estudio o análisis con sentido general, vocacional y profesional; contribuyen al conocimiento de la educación, 
como ámbito o parcela de realidad cognoscible, diversas disciplinas científicas y, de manera singular, la Pedagogía (Touriñán, 1987, 1989 y 2017; Tibble, 1969).

La Pedagogía como disciplina científica es teoría, tecnología y práctica o investigación activa de la educación. La Pedagogía, como conocimiento de la educación, está sometida a los principios de metodología y a principios de investigación, igual que cualquier disciplina científica (Touriñán, 2008 y 2016; Touriñán y Sáez, 2015).

La pedagogía como carrera es el conjunto de materias que se estudian dentro de un plan de estudios con el objetivo de obtener un título (en España, debe estar ajustado a directrices de carácter oficial y validez nacional y habilita para el ejercicio profesional en funciones pedagógicas de acuerdo con las disposiciones vigentes). En la carrera de pedagogía no solo hay Pedagogía como disciplina. La Pedagogía como disciplina se desagrega en disciplinas académicas sustantivas y en asignaturas del plan de estudios y, además de disciplinas y asignaturas de Pedagogía, en la carrera de pedagogía se estudian otras materias formativas que interpretan la educación desde sus propios desarrollos científicos. Así, en la carrera, al lado de materias derivadas de la Pedagogía, hay materias aplicadas derivadas de la Psicología, la Antropología, la Filosofía, la Biología, la Historia, etc. En la carrera de pedagogía, la Pedagogía, como disciplina científica y como disciplina sustantiva, convive con disciplinas aplicadas de otras ciencias y con las disciplinas aplicadas de la Pedagogía (Touriñán, 2017, 2019a y 2019b).

El primer desarrollo doctrinal que hice de estas ideas (Touriñán, 1987, 1988 y 1989) se amplió en (Touriñán, 2008 y Touriñán y Sáez, 2012). En el momento actual (Touriñán, 2016, 2017 y 2020) estoy trabajando sobre la importancia de la teoría de la educación en la construcción de mentalidad pedagógica y el desarrollo de principios de intervención que dan fundamentación a la mirada pedagógica, entendida como representación mental que tiene el pedagogo de su actuación técnica, o lo que es lo mismo, la visión crítica que tiene el pedagogo de su método y de sus actos como tal.

En este trabajo me preocupa el alcance de la teoría de la educación en la carrera de Pedagogía; es decir, me preocupa el ámbito disciplinar de la teoría de la educación dentro de la carrera. Y esta preocupación no se resuelve, si no nos preguntamos por las relaciones y diferencias entre la Pedagogía como disciplina, la teoría de la educación como disciplina y las posibles asignaturas de teoría de la educación en un plan de estudios de pedagogía, como carrera.

La cuestión de la investigación disciplinar es una cuestión abierta y uno de los problemas básicos en la investigación disciplinar es el de la demarcación de ámbitos de competencia. La disciplina que se enseña en un plan de estudios se identifica, ordinariamente, con el conjunto de conocimientos consolidados por la investigación en ese ámbito y ordenados curricularmente. Detrás de esos conocimientos consolidados existe una investigación dedicada al desarrollo y validación de modelos de indagación adecuados a los problemas específicos de ese campo y al conjunto de conocimientos alcanzados sobre los problemas específicos del campo con esos modos de indagación y que, justamente, son problemas específicos del campo, porque así se puede probar desde la racionalidad de la concepción de cada disciplina en concreto.

En el caso de la educación, tan urgente como la investigación en la disciplina, es la investigación de la disciplina. El problema básico no es tanto la productividad del supuesto (inferencias y aplicaciones de la concepción de la disciplina) como la racionalidad de la propia concepción de la disciplina (su justificación y vías de investigación que se paralizan o dificultan desde la propia concepción de la disciplina). 
La disciplina como 'disciplina a enseñar' (el contenido de la asignatura en el plan de estudios), como 'disciplina a investigar' (investigación "de" la disciplina, su concepto y sentido) y como 'disciplina de investigación' (investigación "en” la disciplina, la metodología de creación de conocimiento en la disciplina) son cuestiones importantes, tanto desde el punto de vista de la formación de profesionales de un ámbito, como si lo que se pretende es identificar una asignatura o razonar acerca de la competencia de una disciplina concreta. La mentalidad disciplinar reclama la investigación de y en la disciplina y la formación de los profesionales en ella, para que puedan responder con seguridad a las cuestiones teóricas y prácticas y a la relación teoría-práctica, que es el núcleo central de la mentalidad pedagógica (Touriñán, 2016 y 2017).

De lo que se trata en este caso es de justificar la racionalidad de la propia concepción de la disciplina y la ubicación de la teoría y la práctica dentro de la Pedagogía. Sin pretensión de ultimidad, pero con una clara convicción de que el modo de aclarar y simplificar el panorama conceptual es exponer los argumentos para que se juzguen, voy a argumentar en este artículo sobre tres cuestiones:

- La pluralidad semántica de 'teoría de la educación' y pluralidad de investigaciones teóricas de la educación en la carrera de pedagogía

- El lugar de las investigaciones de la Teoría de la Educación dentro de la Pedagogía (la generación de disciplinas y el conocimiento institucionalizado de la educación)

- La racionalización del concepto de Teoría de la Educación: las acepciones de teoría de la educación, atendiendo al crecimiento del conocimiento de la educación, y la importancia de las pedagogías aplicadas.

\section{2. “Teoría de la educación" Pluralidad semántica y pluralidad de investigaciones teóricas de la carrera de pedagogia}

Imagínense una ficción: Kant en su cátedra y en su seminario de Pedagogía en Könisberg y al lado, en otra aula, a Herbart, en su cátedra y en su Seminario de Pedagogía. El primero dice que la Pedagogía es filosofía aplicada a la educación que permite transformar la animalidad en humanidad. El segundo dice que la Pedagogía es una ciencia en vías de construcción que tiene que generar sus propios conceptos y reflexionar con ellos para proporcionar visión crítica de su método y de sus actos al pedagogo y dejar de ser solo una lejana provincia conquistada por extranjeros.

Es una ficción imaginaria la coetaneidad, pero no el contenido de sus tesis. Kant ocupa la cátedra de Filosofía en Könisberg en 1770 y allí fue, después, Rector y decano de su facultad e impartió en 1786 un Seminario de Pedagogía que dio lugar al libro Pedagogía en 1803, editado sobre los apuntes recogidos por su alumno F. Th. Rink en el Seminario, con el visto bueno del profesor (Kant, 2003).

Por su parte, Herbart, ocupa en 1809 la cátedra vacante de Kant, cinco años después de su muerte (1804). En 1806, siendo profesor de la universidad de Gotinga, Herbart publica su Pedagogía General. Cuando se incorpora a Könisberg, sigue trabajando en la ciencia pedagógica y en 1810 establece un Seminario pedagógico con una escuela experimental aneja para prácticas didácticas.

Kant representa la utilidad de los conceptos filosóficos en la educación y hoy Kónisberg es el territorio ruso de Kaliningrado y su universidad es la Universidad I. Kant, en su honor. Herbart es el origen de la construcción de los conceptos propios, autóctonos, con significación intrínseca al ámbito de educación y todavía no tiene una universidad que reconozca su relevancia, ni siquiera es el nombre de una facultad de Pedagogía. 
A lo largo de los siglos XIX y XX entre los postulados de Kant para la Pedagogía y los postulados de Herbart para la Pedagogía se desarrolla también la corriente de pensamiento que entiende la Pedagogía solo como una aplicación e interpretación de teorías de otras ciencias. La visión más fuerte de la pedagogía como la aplicación de las ciencias de la naturaleza y de las ciencias humanas y sociales a la educación, construyendo teorías prácticas, es la corriente conocida como Pedagogía crítica de la segunda mitad del siglo XX (Novack, 1977; Carr y Kemmis, 1988; Gowin, 1963 y 1972).

Esa pedagogía crítica, cuyo sustrato más valioso son las llamadas teorías prácticas, no han impedido que, desde Herbart, y contando con las aportaciones doctrinales de Dilthey y Nohl, se haya desarrollado, después de la Escuela activa y Nueva, la Pedagogía, como disciplina con autonomía funcional al lado de otras disciplinas científicas que tiene, como ellas, teorías sustantivas y tecnologías específicas, capaces de construir conceptos autóctonos, propios del ámbito de realidad que estudian Dilthey, 1965; Nohl, 1968; Touriñán, 1987 y 2014).

Herbart reclama para el educador la mirada pedagógica, bajo la idea de "círculo visual propio" que él construye desde la Pedagogía, algo que, según sus propias palabras, olvidan enteramente formarse la mayoría de los que educan antes de entregarse a ese empeño. Nos dice Herbart que: “La mayoría de los que educan olvidan enteramente formarse un círculo visual propio antes de entregarse a ese empeño; les surge poco a poco en su trabajo (...), si realmente se desarrolló así (el niño), hay que felicitarse por ello" (Herbart, 1806, p. 1). Frente a este tipo de actuación, Herbart quiere construir un saber que le proporcione razones para fundamentar por qué un educador debe seguir actuando del modo en que lo hace, o por qué debe cambiarlo: "Un maestro de escuela de aldea, de 90 años, tiene la experiencia de su rutina de 90 años; posee el sentimiento de sus largas fatigas, pero ¿tiene también la crítica de su método y de sus actos?" (Herbart, 1806, p. 5).

La ciencia de la educación en Herbart supone la utilización de datos; pero la teoría hay que construirla con autonomía funcional, con autoctonía, porque los datos se interpretan desde un entramado conceptual con significado intrínseco a la educación: “Lo que debe hacer la pedagogía es deliberar sobre sus propios conceptos y cultivar una reflexión independiente. De esta forma llegaría a ser el centro de un círculo de investigaciones y no correría el peligro de ser gobernada por un extranjero como lejana provincia conquistada" (Herbart, 1806, p. 8. La cursiva es mía).

En el siglo XX hemos superado los debates epistemológicos del modelo tradicional de evolución del conocimiento de la educación, que presentaba como incompatibles la filosofía, la ciencia, las ciencias de la educación y las teorías prácticas (Touriñán, 1987). Hoy sabemos que las viejas disputas entre la posición alemana, la posición francesa y la angloamericana, pueden ser integradas en el conocimiento de la educación estableciendo límites de credibilidad de sus postulados con rigor lógico y empírico en los razonamientos probatorios (Touriñán, 2014). El desarrollo epistemológico del siglo XXI sobre ciencia general y aplicada y sobre el desarrollo de principios generales de metodología de investigación producidos a partir de Popper en las corrientes historicistas y en las corrientes comprensivas de Toulmin, Bunge, Suppe, Ladrière y otros (Touriñán y Sáez, 2015), son el entramado epistemológico que permite trabajar con seguridad la complejidad del campo de la educación dentro de las ciencias sociales (Touriñán, 2019a y 2019b; Touriñán y Sáez, 2015; Naval y Altarejos, 2000; Escámez, 2007; Gil Cantero, 2011; SI(e)TE, 2018; Jover y Thoilliez, 2010; Luque, 2019; Caudo, 2013; Coham, 1998; Gil Cantero, Lorenzo y Trilla, 2019; Rabazas, 2014; Guelman, Cabaluz y Salazar, 2018; Guerreiro, 2013; Rodríguez, 2006; Vega Román, 2018; Vera-Rojas, Massón y Vera, 2018; Vázquez, 2004 y 2018; Colom, 2018; Suppe, 1979; Toulmin, 2003; Bunge, 1975; Ladrière, 1977). 
Hoy se acepta el principio general metodológico de la investigación científica de “complementariedad" en las elaboraciones epistemológicas. Y debido a esa complementariedad, no hay exclusión entre las elaboraciones de pedagogía como carrera y como disciplina y las elaboraciones propias de las ciencias de la educación y las elaboraciones propias de la teoría, la tecnología y la investigación activa. Otra cosa es que haya personas fundamentalistas que pretendan reducir la posible investigación teórica de la educación a su interés particular (Touriñán, 2015b, 2016, 2017, 2018c y 2019a).

En Pedagogía distinguimos investigaciones teóricas acerca de la educación (filosofías de la educación y teorías interpretativas) investigaciones de teoría práctica, investigaciones de teoría como nivel de análisis epistemológico (sean de didáctica, de pedagogía general o de pedagogía comparada) e investigaciones de teoría de la educación como disciplina académica sustantiva que, desde Herbart, se ha llamado disciplina de "pedagogía general" y que Nohl llamó "teoría de la educación", restringiendo el uso del término (Cuadro 1).

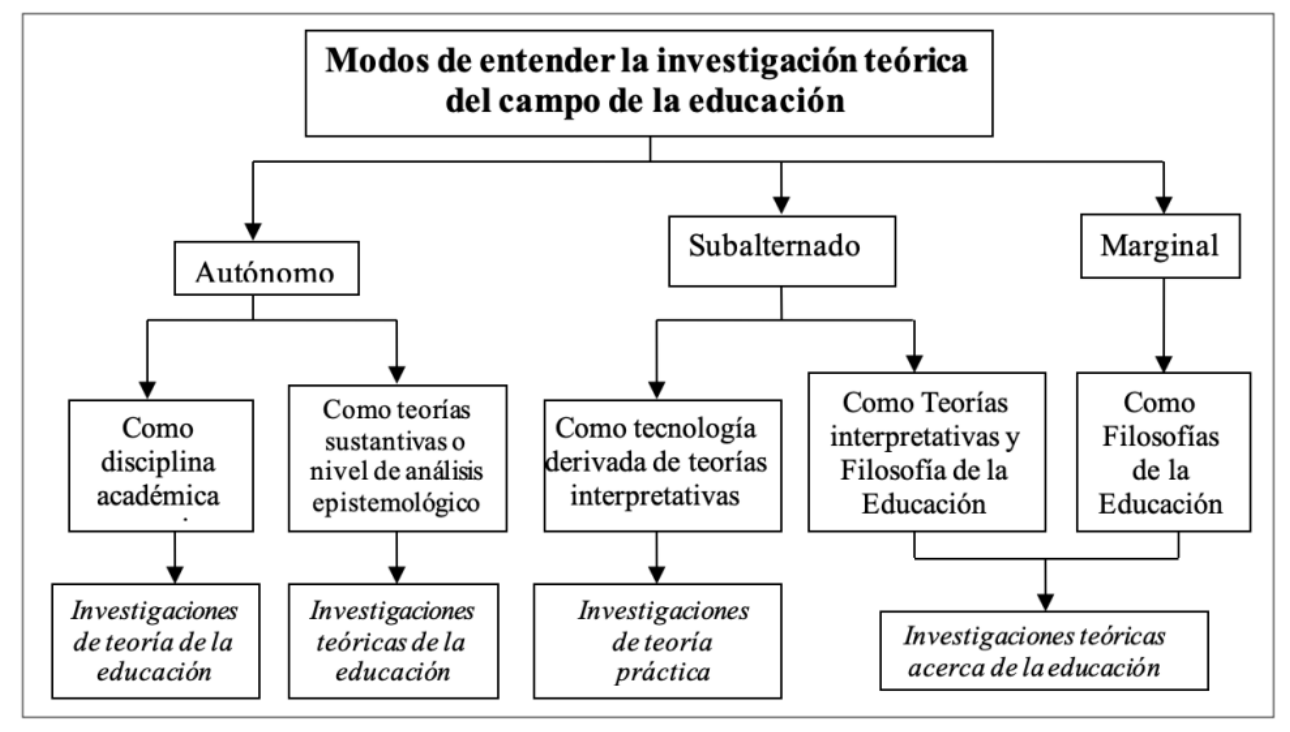

Cuadro 1: Investigaciones teóricas del campo de la educación

Fuente: Touriñán, 2016, p. 901.

Hoy en día se asume que puede existir una ciencia propia de lo social, que se llama Sociología y existen otras ciencias que interpretan lo social (ciencias de lo social, como psicología social, antropología social, etcétera). Esto mismo pasa en Psicología y en Pedagogía y en Medicina (hay Medicina como disciplina y hay ciencias de la salud, como la Biología u otras). Hay Pedagogía y hay ciencias de la educación (Sociología de la educación, Psicología de la educación y otras). Y dentro de cada disciplina científica, en nuestro caso, dentro de la Pedagogía, hay disciplinas sustantivas que especializan la ciencia generando sus modos de prueba específicos desde conceptos propios, autóctonos, de la disciplina sustantiva (ya sea pedagogía general -teoría de la educación como disciplina sustantiva-, didáctica o pedagogía comparada). Estas tres disciplinas sustantivas tienen objetos de conocimiento distintos y especializan la disciplina científica misma, respecto del conocimiento de la educación, en la intervención pedagógica, la enseñanza y el sistema educativo, respectivamente). 
Hoy en día, además, se asume que cada disciplina científica (pedagogía, psicología, sociología, antropología, etc.) se especializa en su propia tarea y puede interpretar otros ámbitos con los conceptos autóctonos que elabora, por eso hay sociología general y sociología aplicada (sociología de la familia, de la educación, de las religiones, etcétera). Lo importante, hoy, es que se distingue entre ciencia general y ciencia aplicada. La ciencia general especializa la disciplina, la ciencia aplicada especializa la tarea, es decir su campo de aplicación. Hay Pedagogía general y aplicada, Sociología general y aplicada, Antropología general y aplicada, Didáctica general y Didácticas específicas o Didáctica aplicada, Filosofía y filosofías aplicadas, etcétera, (Touriñán, 2018b y 2019a; González Álvarez, 1977). Los distintos modos de entender el conocimiento de la educación han generado una diversidad necesaria de conocimientos teóricos de la educación, según el tipo de problemas que se estén analizando. A veces necesitaremos teorías sustantivas de la educación (para explicar y comprender la educación en conceptos propios); a veces necesitaremos teorías prácticas y teorías interpretativas (para orientar la intervención hacia fines socialmente prescritos o para comprender la intervención educativa en términos validados por otras disciplinas consolidadas, como la Psicología, la Sociología, etc.); a veces, necesitaremos teorías filosóficas (en plural) de la educación, que se centran en conocer las consecuencias que se derivan para la educación de una determinada concepción de vida (así se hacen las filosofías de la educación o teorías filosóficas, en plural, de la educación) y, a veces, necesitaremos teoría filosófica (en singular) de la educación que se centra en hacer análisis fenomenológico, dialéctico, crítico-hermenéutico o lingüístico de un fin en sí, estudiar la lógica interna del fin dentro del sistema conceptual de 'educación', etcétera (así se hace la filosofía de la educación o teoría filosófica, en singular, de la educación).

En la actualidad, seguimos avanzando hacia la Pedagogía como disciplina con autonomía funcional, que genera conceptos autóctonos -propios y no subalternados- y que valora como educativo cada medio que utiliza: avanzamos en la perspectiva mesoaxiológica de la Pedagogía como disciplina (Touriñán, 2017).

Normalmente, la denominación de la disciplina delimita con precisión el contenido de la misma. Pero, en el caso de la Teoría de la Educación, no ocurre lo mismo. Es precisamente el sentido de la disciplina el que tiene que perfilarse. Como dijo el profesor R. Marín: "las presiones de las fuerzas que de hecho dominan la universidad y se proyectan en la elaboración de planes de estudios; la realidad del movimiento pedagógico, con una producción que desborda la capacidad de información y síntesis de los individuos y grupos que han de tomar las decisiones y la no abundancia de reflexiones que sin olvidar estos datos se centren en una más precisa delimitación del contenido y método de cada ciencia, evitando las presiones perturbadoras; todo ello confunde y complica el panorama conceptual y terminológico". (Marín 1983, p. 15. La cursiva es mía).

Desde mi punto de vista, el objeto 'educación' requiere todos los tipos de estudios, con las formas de conocimiento más adecuadas para ello, de manera tal que seamos capaces de hacer frente, no sólo a la descripción, explicación, comprensión, interpretación y transformación, de la educación, sino también a la generación de conceptos con respeto a los principios de metodología y a los principios de investigación pedagógica, para el uso, construcción y desarrollo del ámbito de realidad 'educación' que es el objeto y la meta del quehacer pedagógico. Respecto de la educación Hay pluralidad de investigaciones teóricas y el concepto de teoría de la educación adquiere polisemia en relación con el tipo de investigaciones teóricas que integra. 
Los avances realizados en el estudio de la educación como objeto de conocimiento, nos capacitan para identificar y diferenciar en la carrera de pedagogía la aportación de diversas disciplinas científicas (aprendemos Pedagogía, Filosofía, Psicología, Antropología y otras disciplinas en distinta proporción e intensidad) y también esos avances nos capacitan para distinguir investigaciones teóricas acerca de la educación (filosofías de la educación y teorías interpretativas) investigaciones de teoría práctica, investigaciones de teoría como nivel de análisis epistemológico (sean de didáctica, de pedagogía general o de pedagogía comparada) e investigaciones de teoría de la educación como disciplina académica sustantiva. El principio de complementariedad metodológica en la investigación pedagógica justifica esta tendencia (Touriñán, 2017 y 2012a).

Con todo, hoy en día, seguimos avanzando hacia la Pedagogía como disciplina con autonomía funcional que valora como educativo cada medio que utiliza desde el conocimiento de la educación: es la perspectiva mesoaxiológica de la Pedagogía. Ese saber de perspectiva mesoaxiológica, que valora cada medio como educativo, es el que corresponde a la Pedagogía y la Pedagogía es el saber que necesitamos para construir ámbitos de educación, es decir, para transformar en educativo cualquier medio que utilicemos (http://dondestalaeducacion.com/conceptos.html).

\section{Las razones pragmáticas en la parcelación de materias escolares no deben conculcar las razones epistemológicas disciplinares.}

De manera genérica es posible plantear y reconocer problemas genuinos de investigación disciplinar desde las tres acepciones asumidas para las disciplinas en la comunidad científica: como disciplina a enseñar (asignatura de planes de estudios), como disciplina a investigar (investigación de la disciplina, justificación y validación de la propia disciplina y de su definición y sistema conceptual, que justifica lo que debería investigarse y qué cuestiones se investigan) y como disciplina de investigación (investigación en la disciplina, la productividad y la metodología de conocimiento propias de la disciplina; es el trabajo de investigación "en y desde" la disciplina, es decir, cómo se investiga en la disciplina), que resumimos gráficamente en el Cuadro 2.

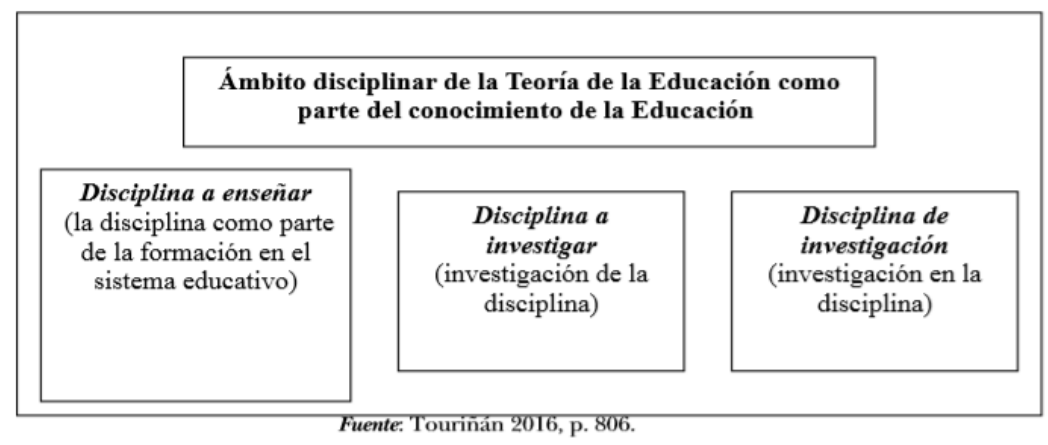

Cuadro 2: Ámbito disciplinar de la teoría de la educación

Esta distinción es especialmente significativa, porque los contenidos de una disciplina se validan por coherencia con la investigación de la disciplina, es decir, por coherencia con la concepción del campo y crecen por productividad o crecimiento del conocimiento del campo, de acuerdo con el desarrollo de la investigación en la disciplina (Touriñán, 2019a y 2018b). 
El problema real, para mí está en la posibilidad de generar asignaturas de planes de estudios en los que por razones pragmáticas podemos mezclar bajo la idea de libertad de cátedra contenidos de Filosofías de la educación, contenidos de pedagogía general, contenidos de teorías interpretativas de la educación, sin que los profesores se hagan responsables de esa mezcla y de la necesaria distinción epistemológica entre disciplinas académicas sustantivas y contenidos de asignaturas. Y esto explica que, incluso defendiendo la misma concepción disciplinar de la Pedagogía, puedan existir diversidad de asignaturas en los planes de estudios particulares de cada universidad.

Las posibilidades de división de disciplinas y de creación de asignaturas en los planes de estudios obedecen a razones pragmáticas, no vinculadas al criterio ontológico y epistemológico que hay que esgrimir al hablar de los límites de identidad de las disciplinas sustantivas. En cualquier caso, el nivel escolar en el que se imparte la asignatura, la competencia del profesor y el tiempo son condicionantes pragmáticos y específicos de las asignaturas de planes de estudios.

Como asignatura de plan de estudios, por ejemplo, la Pedagogía General obedece a razones pragmáticas, distintas del criterio epistemológico y ontológico de las disciplinas académicas sustantivas, aunque lógicamente debe tener contenido propio de Pedagogía general al menos en parte, para poder denominarse con propiedad asignatura de "pedagogía general". Como asignatura se identifica con la organización curricular de la disciplina, para un tiempo dado y en un plan de estudios concreto, en orden a la enseñanza y al aprendizaje de determinados conocimientos consolidados en la disciplina. Es frecuente que como asignatura de plan de estudios la Pedagogía General responda sólo a una parte de la temática consolidada en la disciplina académica sustantiva (la competencia del profesor, el lugar de la asignatura en la organización vertical del plan de estudios y el tiempo de docencia, son factores condicionantes). Precisamente por ello, existen universidades en las que la disciplina académica sustantiva se responde desde una, dos o tres asignaturas del plan de estudios. Son condiciones de tipo institucional y administrativo las que sesgan el contenido de la disciplina. Este tipo de condiciones es el que permite razonar acerca de la presencia suficiente o insuficiente de la disciplina en el plan de estudios y de la buena o mala articulación de la misma en el plan. Y esto ocurre de manera singular y distinta en cada país y, si hay una política educativa capaz de conculcar la homogeneidad de planes de estudios y su validez a nivel nacional, yo me atrevería a decir que ocurre de manera singular y distinta en cada universidad. Tal acontecimiento, desde la perspectiva epistemológica y de la racionalidad administrativa bien entendida, si ocurre realmente, es un despropósito que va en detrimento de la calidad de la formación de los profesionales de la educación.

A la hora de identificar la asignatura conviene tener presente estas matizaciones, porque, en caso contrario, se confunde el discurso. Si nosotros, a pesar de lo argumentado, identificamos la Pedagogía General como disciplina con la asignatura particular del plan de estudios, estamos limitando la enseñanza de la Pedagogía, como disciplina sustantiva, a aquellos aspectos que se están impartiendo circunstancialmente y por razones distintas de los criterios ontológico y epistemológico utilizados en la investigación de la disciplina, tales como el tiempo, el lugar de la disciplina en un determinado plan de estudios, la preparación del profesor o las presiones institucionales que han hecho posible que la disciplina de Pedagogía General sea en cada plan de estudios la asignatura que es, o pudiera llegar a ser o existir.

En el plan de estudios podríamos tener, por ejemplo, por razones pragmáticas, una asignatura cuyo contenido se centrara en las cuestiones filosófico-antropológicas de la educación y en las teorías 
prácticas; se podría denominar "Teorías de la Educación" y "Filosofía de la Educación" o "Antropología de la educación", haciendo referencia con la denominación a las investigaciones teóricas acerca de la educación o a una parte del contenido que les corresponde epistemológicamente a esas disciplinas.

También podríamos tener además otras dos asignaturas que desarrollarían el contenido de la disciplina sustantiva Pedagogía General. Ambas asignaturas podrían denominarse con propiedad Pedagogía General I y II. En este caso, como asignatura de plan de estudios, estamos identificando la Pedagogía General, con una parte del contenido de la disciplina académica sustantiva que se justifica por razones pragmáticas, de tiempo, lugar en el plan de estudios y preparación del profesor, así como por los objetivos del plan de estudios.

Y por supuesto también podríamos tener una sola asignatura que diera, por razones pragmáticas, contenidos de pedagogía general, contenidos de filosofía de la educación y contenidos de teorías filosóficas de la educación. Su denominación de asignatura podría hacer referencia a las tres disciplinas o a una de ellas que se destaca por encima de las otras en el reparto de contenidos de asignatura. Esto es posible desde el punto de vista pragmático de organización de un plan de estudios, porque, de acuerdo con las tesis expuestas, puede mantenerse, respecto de cualquier relación de contenidos de asignatura de plan de estudios, lo siguiente (Touriñán, 2016):

1. Los contenidos de una asignatura de plan de estudios no se corresponden necesariamente con los contenidos de una disciplina sustantiva. Por razones pragmáticas, que hemos visto ya, pudieran existir dos o tres asignaturas que repartan el contenido de la disciplina sustantiva o que varias disciplinas se integren en una asignatura con contenido de cada una de ellas.

2. Los contenidos que se enseñan en una asignatura de plan de estudios son aquellos que no sólo están avalados por la investigación de y en las disciplinas sustantivas que la integran, sino también que responden a los objetivos de la asignatura y del curso dentro del plan de estudios.

Pero, siendo esto así, no se sigue que por razones pragmáticas un profesor se olvide de transmitir en su asignatura la diferencia epistemológica que hay entre los contenidos de su asignatura cuando integra disciplinas distintas bajo una denominación pragmática de asignatura que está permitida legalmente por razones académico-administrativas.

Es posible parcelar el conocimiento de la educación en disciplinas. El crecimiento del conocimiento de la educación puede generar nuevas disciplinas. En la carrera de Pedagogía aprendemos a descubrir, inventar e innovar en educación como actividad, como ámbito de realidad y como ámbito de conocimiento, perfeccionando nuestro conocimiento del ámbito (Belth, 1971; Popper-Eccles, 1980; Popper, 1984; Touriñán y Longueira, 2018; Touriñán, 2014, 2018a, 2019a y 1987; Hirst, 1974; Broudy, 1977; Toulmin, 1977; Toulmin, Rieke y Janik, 1979; Romero, 2006; Walton, 1974, 1963 y 1971; Tibble, 1969; Peters, 1969 y 1977; Uljens, 2001). Hacemos asignaturas por razones pragmáticas. Y algo hacemos mal, cuando en nuestros centros universitarios damos la impresión de que los intereses de grupo o escuela se ponen por encima de los desarrollos epistemológicos de la Pedagogía con las argucias político-administrativas que se puedan generar par la creación de asignaturas. 
Y si esto es así, se sigue que, las asignaturas pueden mezclar pedagogía general, filosofía de la educación y teorías filosóficas y teorías interpretativas de la educación y teorías prácticas, por razones pragmáticas, pero no deben conculcar las razones epistemológicas de la disciplina sustantiva en ningún caso. Y esto afecta, como ya he dicho a la calidad de los planes de estudios, a las carrearas que se diseñan, a la disciplina científica misma y a las facultades que las albergan.

\section{La teoría de la educación como disciplina es el núcleo de la mentalidad pedagógica específica.}

Cuando hablamos de la investigación "de" la disciplina, o de la Teoría de la Educación como disciplina a investigar, estamos haciendo hincapié en el sentido de la disciplina; es decir, en la justificación y validación de la propia concepción del campo, o lo que es lo mismo, en la racionalidad de la concepción del campo.

Qué sea la disciplina de Teoría de la Educación, es una cuestión abierta en la que existen respuestas susceptibles de sistematización. A la hora de indagar el sentido de la disciplina puede mantenerse como hipótesis que la concepción de la teoría de la educación como disciplina se vincula a la idea que tenemos del conocimiento de la educación. A esta cuestión he dedicado muchos años de estudio y muy diversas publicaciones desde 1987 (Touriñán 1987, 1989a, 2008, 2016). La vinculación entre conocimiento de la educación y concepto de Teoría de la educación se expresa del siguiente modo (Touriñán, 2017):

La Teoría de la Educación es, en principio, conocimiento de la educación, que es un objeto complejo.

El conocimiento de la educación crece y no ha sido siempre contemplado del mismo modo,

si bien, como conocimiento, hace referencia a los niveles epistemológicos y a las diversas formas de racionalidad.

El estudio de los cambios de supuestos en el conocimiento de la educación es una forma adecuada de conocer los distintos modos de entender la Teoría de la Educación.

En la evolución del conocimiento de la educación, se acepta tradicionalmente que es posible establecer tres etapas, cada una de ellas con su propio planteamiento. Esta clasificación, que se conoce como modelo tradicional de evolución del conocimiento de la educación, fue resumida por G. Avanzini (1977):

- Etapa de la filosofía. En esta etapa el conocimiento que se legitima como conocimiento de la educación es estrictamente filosófico, de las finalidades de vida.

- Etapa de la ciencia de la educación. El conocimiento que se legitima como conocimiento de la educación es estrictamente positivista, de los medios para fines dados.

- Etapa de las ciencias de la educación. El campo de la educación es suficientemente amplio y complejo como para que diversas ciencias desempeñen su cometido de estudio.

Entendemos que este modelo, al que le he dedicado atención en otros trabajos (Touriñán 1987; Touriñán y Rodríguez, 1993a y 1993b; Touriñán, 2014 y 2016) debe ser descartado como tipificación de la evolución del conocimiento de la educación por muy diversas consideraciones que expongo de forma sintética, a continuación.

El modelo tradicional mantiene que los ejes que determinan las tres etapas y, por tanto, la evolución del conocimiento de la educación son dos: 
La etapa histórica como la preponderancia de una determinada concepción acerca de la educación como objeto de conocimiento en una época o periodo temporal determinado (planteamiento básico de la etapa)

La especialización progresiva del conocimiento de la educación.

Hemos de reconocer que resulta plausible afirmar con criterio de especialización que primero fue la Filosofía, después la ciencia y luego las ciencias de la educación. Pero no debemos olvidar que la preponderancia de una determinada idea sobre otra es un criterio de estimación social, no necesariamente es criterio epistemológico. Si se toma como criterio epistemológico, estamos afirmando que el planteamiento filosófico sería una especie a extinguir; un saber primitivo indiferenciado que va siendo vaciado progresivamente por las ciencias particulares. La realidad de los hechos no confirma tal cosa. Existen estudios actuales que prueban que la Filosofía surgió desde el comienzo como una disciplina diferenciada de las restantes. Los problemas que plantean los filósofos y los científicos son distintos, lo cual quiere decir que el descenso del número de personas dedicadas a los problemas filosóficos, no altera la pertinencia lógica de las preocupaciones intelectuales en las que se ocupan (Touriñán, 2014).

Esta posición tradicional es francamente verosímil, porque la idea de especialización configura modos distintos de entender el objeto de conocimiento. Sin embargo, el modelo tradicional no cubre la función de evolución del conocimiento de la educación con precisión, porque carece de rigor lógico (pertinence) y de significatividad (relevance, significativity) (Touriñán, 2018a y 2018b).

El modelo tradicional no tienen rigor lógico, porque, si lo que define una etapa es la preponderancia de un tipo de pensamiento (Filosofía, ciencia, o ciencias), deja abierta la posibilidad de clasificar cada obra concreta de pensamiento en dos etapas distintas. En efecto, cada obra puede incluirse en la etapa en la que predomina la forma de pensamiento utilizada en esa obra, y también puede incluirse en la etapa correspondiente al momento en que se escribió la obra, aunque el pensamiento predominante en ese momento no sea el mismo de la obra.

Si hoy escribimos sobre educación una obra con mentalidad de etapa de la Filosofía, puede clasificarse en esa primera etapa y puede clasificarse dentro de la última etapa, porque la hemos escrito en el momento de vigencia de esta tercera etapa. Esta ambigüedad reduce la significatividad de nuestra hipotética obra, porque su valor relativo en la evolución del conocimiento de la educación es distinto según se incluya en una u otra etapa, e, incluso, en algún caso, por efecto de la tendencia predominante, podría pasar desapercibida o rechazada como no significativa por ir contra corriente o estar fuera de la corriente dominante.

Rechazamos el modelo tradicional, porque el concepto de "etapa" no resuelve la inclusión de una obra de manera suficiente como criterio temporal con referencia al concepto de pensamiento predominante en una etapa, de manera tal que una determinada obra es susceptible de inclusión en dos etapas distintas, generando problemas de rigor lógico y de significatividad.

Pero, fundamentalmente, rechazamos el modelo tradicional, porque no discrimina realmente respecto de la evolución del conocimiento de la educación. Es un hecho que entre su etapa de la ciencia de la educación y su etapa de las ciencias se mantiene la misma consideración general de la educación como objeto de conocimiento: en ambos casos la educación se resuelve en términos de otra ciencia. Esas dos etapas no suponen dos corrientes de pensamiento distinto acerca del conocimiento de la educación. Ambas etapas coinciden en defender que la educación se resuelve en términos de las 
teorías interpretativas. Ambas etapas niegan la posibilidad del estudio científico de la educación con autonomía funcional. Ambas etapas se diferencian entre sí, porque, en la etapa de la ciencia de la educación, la educación es un marco de referencia sin significación intrínseca que se resuelve utilizando los principios de una sola disciplina generadora; en la etapa de las ciencias de la educación se admiten diversas disciplinas generadoras. El techo del modelo tradicional es la negación de la autonomía funcional en el estudio de la educación, y por consiguiente, hablando con propiedad, el modelo tradicional es sólo el modelo de los estudios científicos subalternados de la educación, no de la evolución del conocimiento de la educación (Touriñán, 2017, caps. 2 y 3).

Por analogía con los estudios realizados acerca de la evolución de otros saberes, y teniendo en cuenta que el modelo de crecimiento es aplicable a la evolución del conocimiento de la educación, se defienden en la investigación pedagógica tres corrientes distintas acerca del conocimiento de la educación que se definen, respectivamente, no por el método que utilizan, sino por la consideración que hacen de la educación como objeto de conocimiento, porque no es lo mismo pensar la educación como un objeto de estudio genuino con conceptos que tienen significación intrínseca al ámbito "educación", que entender la educación como un objeto de estudio que se resuelve en conceptos de las disciplinas generadoras o que concebirla como una actividad práctica (Touriñán 1987, 1990a, 2008, 2014, 2016 y 2017; Touriñán y Rodríguez, 1993a; Touriñán y Sáez, 2015; Rodríguez, 2006; Naval, 2008, Touriñán y Longueira, 2018).

Las tres corrientes de la educación se denominan, según la consideración que hacen de la educación como objeto de conocimiento, del siguiente modo en el modelo de crecimiento del conocimiento de la educación:

1. Corriente marginal del conocimiento de la educación.

2. Corriente subalternada del conocimiento de la educación.

3. Corriente autónoma del conocimiento de la educación.

Cada una de estas corrientes contribuye a conformar una determinada mentalidad pedagógica, se distingue básicamente por el tipo de respuesta a los siguientes criterios:

- La consideración de la educación como objeto de estudio.

- El conocimiento que debe obtenerse para saber educación.

- El modo de resolver el acto de intervención.

- La posibilidad de construir ciencia de la educación.

Cada corriente mantiene un modo distinto de entender el conocimiento de la educación. Cada modo de entender el conocimiento de la educación ha generado un conjunto de conocimientos acerca de la educación y del contenido de la disciplina de Teoría de la educación, en absoluto, despreciables. Las tres corrientes son modos legítimos de abordar la educación. Las aportaciones de cada corriente son la base de su fuerza dentro del gremio de los profesionales de la educación. Cada corriente asume que la educación es un ámbito de realidad susceptible de ser conocido de diversas formas (racionalidad científico-tecnológica, racionalidad práxica, racionalidad literaria y artística, etc.) que tienen sus peculiares modos de prueba y su particular modo de respuesta a los niveles epistemológicos teoría, tecnología y práctica, desde el marco de cada corriente del conocimiento de la educación (Cuadro 3). 


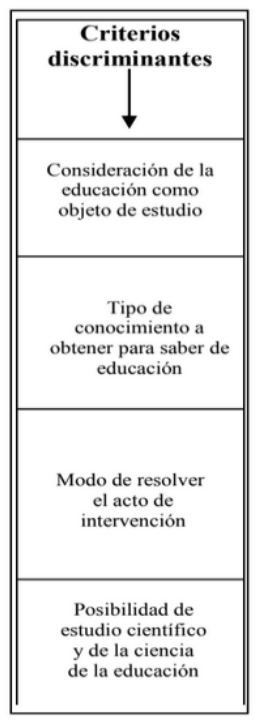

\begin{tabular}{|c|c|c|}
\hline $\begin{array}{l}\text { Corriente marginal } \\
\text { Estudios filosóficos } \\
\text { cosmovisionarios }\end{array}$ & $\begin{array}{c}\text { Corriente de } \\
\text { subalternación } \\
\text { Estudios interpretativos } \\
\text { cientificos y filosóficos }\end{array}$ & $\begin{array}{l}\text { Corriente autónoma } \\
\text { Estudios de Pedagogia como } \\
\text { disciplina con autonomia } \\
\text { funcional }\end{array}$ \\
\hline $\begin{array}{l}\text { La educación no es } \\
\text { un objeto de estudio } \\
\text { genuino. Es una } \\
\text { actividad práctica }\end{array}$ & $\begin{array}{l}\text { La educación es un objeto } \\
\text { de estudio genuino que se } \\
\text { resuelve en términos de las } \\
\text { disciplinas generadoras }\end{array}$ & $\begin{array}{l}\text { La educación es un objeto de } \\
\text { estudio genuino que permite } \\
\text { generar conceptos propios del } \\
\text { ambito }\end{array}$ \\
\hline $\begin{array}{l}\text { El conocimiento } \\
\text { esencial es el de los } \\
\text { fines de vida } \\
\text { deseables }\end{array}$ & $\begin{array}{l}\text { El conocimiento esencial } \\
\text { es el de los medios para } \\
\text { fines dados e elaborados } \\
\text { praxicamente derde la } \\
\text { educación }\end{array}$ & $\begin{array}{c}\text { El conocimiento esencial } \\
\text { es el de fines y medios } \\
\text { lógicamente implicados en el } \\
\text { proceso }\end{array}$ \\
\hline $\begin{array}{c}\text { La intervención } \\
\text { se eresuelve } \\
\text { experiencialmente }\end{array}$ & $\begin{array}{l}\text { La intervención se } \\
\text { resuelve en prescripeión } \\
\text { de reglas avilidadas con } \\
\text { las teorias } \\
\text { interpretativas }\end{array}$ & $\begin{array}{l}\text { La intervención requiere } \\
\text { generar principios de } \\
\text { intervención pedagógica: } \\
\text { establecer vinculaciones y } \\
\text { prescribir reglas validadas } \\
\text { con las teorias sustantivas }\end{array}$ \\
\hline $\begin{array}{l}\text { No es posible el } \\
\text { estudio cientifitoo de } \\
\text { la educación porque } \\
\text { es una actividad } \\
\text { práctica y singular }\end{array}$ & $\begin{array}{l}\text { Es posible el estudio } \\
\text { cientifico de la la } \\
\text { educación. Hay ciencias } \\
\text { de la educación }\end{array}$ & $\begin{array}{l}\text { Es posible la ciencia de la } \\
\text { educación. Hay Pedagogia } \\
\text { como disciplina autónoma } \\
\text { que genera conceptos con } \\
\text { significación intrinseca al } \\
\text { ámbito educación }\end{array}$ \\
\hline
\end{tabular}

Cuadro 3: Corrientes del conocimiento de la educación

Fuente: Touriñán, 2016, p. 109.

Es comprensible que, según la mentalidad pedagógica propia de cada corriente, la investigación y la disciplina de Teoría de la educación se entiendan de modo distinto, por eso, nuestra preocupación fundamental, en este artículo, no se dirige a la fecundidad de las hipótesis de cada corriente, sino a la pertinencia de limitar la significación del conocimiento de la educación a la capacidad de resolución de problemas que se le atribuye a dicho conocimiento en cada corriente.

El objetivo no es negar la fecundidad de cada corriente, y, por tanto, negar la existencia de conocimientos correspondientes a cada corriente, sino razonar acerca de la pertinencia del nombre de "Teoría de la Educación" en cada caso para la disciplina académica derivada de cada corriente.

La cuestión no es que en diversos momentos se le haya llamado disciplina de Teoría de la Educación a cosas distintas, la cuestión es, si hoy hay que llamar disciplina de Teoría de la Educación a todas esas cosas, o hay razones que afectan a las formas de conocimiento y al desarrollo disciplinar que permiten hacer un uso restringido del término "disciplina académica sustantiva de Teoría de la Educación" sin por ello despreciar los otros conocimientos.

La tendencia justificada por la investigación en estos momentos apunta a la segunda alternativa. La Teoría de la Educación como disciplina sustantiva no es un cajón de sastre en el que cabe de todo. Es posible defender un aspecto, parcela o sector de la Pedagogía específico para la disciplina académica sustantiva de Teoría de la Educación, reconociendo al mismo tiempo que otros contenidos, en algún momento incluidos en la disciplina de Teoría, siguen siendo valiosos, pero constituyen los elementos centrales de otras disciplinas. La argumentación básica de esta tendencia se centra en justificar que investigación teórica del campo de la educación no es lo mismo que "disciplina académica sustantiva de Teoría de la Educación".

El conocimiento de la educación tiene su manifestación más genuina en el conocimiento pedagógico, que es el que determina la acción profesional en cada función pedagógica (Touriñán, 2015a, 2017, 2019d y 2020). El conocimiento pedagógico nace del estudio de la intervención, y dado que de todo conocimiento de la educación se deriva a través de la relación teoría-práctica una cierta consideración o recomendación para la intervención, podemos decir que de todo conocimiento de la 
educación se deriva un cierto conocimiento pedagógico. Por la misma razón, podemos decir que toda intervención educativa es, en cierta medida, una intervención pedagógica, porque en toda intervención educativa hay un componente de conocimiento pedagógico, que nace del estudio de la relación teoría-práctica y que no tiene siempre el mismo nivel de elaboración técnica en su manifestación, tal como queda reflejado en el Cuadro 4:

\begin{tabular}{|c|c|c|c|}
\hline $\begin{array}{c}\text { Criterios } \\
\text { discriminantes } \\
\mid\end{array}$ & $\begin{array}{c}\text { Corriente marginal } \\
\text { Estudios filosóficos } \\
\text { cosmovisionarios }\end{array}$ & $\begin{array}{c}\text { Corriente de } \\
\text { subalternación } \\
\text { Estudios interpretativos } \\
\text { interdisciplinares }\end{array}$ & $\begin{array}{c}\text { Corriente autónoma } \\
\text { Estudios de Pedagogía como } \\
\text { disciplina con autonomía } \\
\text { funcional }\end{array}$ \\
\hline $\begin{array}{c}\text { Tipo de } \\
\text { conocimiento a } \\
\text { obtener para } \\
\text { saber } \\
\text { educación. }\end{array}$ & $\begin{array}{c}\text { Fines de vida y } \\
\text { justificación de fines. } \\
\text { Consecuencias que se } \\
\text { deducen para la } \\
\text { educación desde } \\
\text { Teorias filosóficas } \\
\text { cosmovisionarias }\end{array}$ & $\begin{array}{c}\text { Medios, para fines } \\
\text { dados, vinculando } \\
\text { condiciones y efectos a } \\
\text { un acontecimiento } \\
\text { desde } \\
\text { Teorias interpretativas } \\
\text { o Investigaciones } \\
\text { aplicadas }\end{array}$ & $\begin{array}{c}\text { Fines y medios derivados del } \\
\text { proceso de intervención } \\
\text { pedagógica, vinculados a } \\
\text { Teorias sustantivas }\end{array}$ \\
\hline $\begin{array}{l}\text { Modo de } \\
\text { resolver el } \\
\text { acto de } \\
\text { intervención }\end{array}$ & $\begin{array}{l}\text { Utilizando la } \\
\text { experiencia del } \\
\text { acto de } \\
\text { intervención } \\
\text { concreto }\end{array}$ & $\begin{array}{l}\text { Utilizando reglas y } \\
\text { normas derivadas de } \\
\text { Teorias Prácticas y } \\
\text { aplicaciones técnicas }\end{array}$ & $\begin{array}{l}\text { Construyendo reglas y } \\
\text { normas vinculadas } \\
\text { desde } \\
\text { Tecnologias } \\
\text { específicas }\end{array}$ \\
\hline $\begin{array}{c}\text { De dónde } \\
\text { proviene el } \\
\text { componente de } \\
\text { conocimiento } \\
\text { pedagógico en } \\
\text { cada } \\
\text { intervención }\end{array}$ & $\begin{array}{l}\text { De la capacidad de } \\
\text { resolución de } \\
\text { problemas para la } \\
\text { intervención con la } \\
\text { relación teoria- } \\
\text { práctica en la } \\
\text { corriente marginal. }\end{array}$ & $\begin{array}{l}\text { De la capacidad de } \\
\text { resolución de } \\
\text { problemas para la } \\
\text { intervención con la } \\
\text { relación teoría-práctica } \\
\text { en la corriente } \\
\text { subalternada }\end{array}$ & $\begin{array}{l}\text { De la capacidad de } \\
\text { resolución de } \\
\text { problemas para la } \\
\text { intervención con la } \\
\text { relación teoría-práctica } \\
\text { en la corriente } \\
\text { autónoma }\end{array}$ \\
\hline
\end{tabular}

Cuadro 4: Derivación del conocimiento pedagógico según las corrientes.

Fuente: Touriñán, 2016, p. 112.

Después de lo dicho, parece evidente que preguntarse qué conocimiento de la educación se necesita, reclama una respuesta amplia que no quede restringida al conocimiento de la educación que proporcione una de las corrientes. Según el tipo de problemas que estemos planteando, necesitaremos conocimiento autónomo, subalternado o marginal.

\section{La pluralidad de investigaciones teóricas del campo de la educación}

El conocimiento de la educación procede de muy diversas formas de conocimiento y genera muy diversas disciplinas. Hay disciplinas derivadas de la Filosofía, hay disciplinas derivadas de las teorías interpretativas, hay disciplinas derivadas de teorías prácticas y hay disciplinas derivadas de teorías sustantivas.

Los distintos modos de entender el conocimiento de la educación han generado una diversidad necesaria de conocimientos teóricos de la educación, según el tipo de problemas que se estén analizando. Investigaciones teóricas acerca de la educación. Las filosofías de la educación y las teorías interpretativas de la educación.

A veces necesitaremos teorías sustantivas de la educación (para explicar y comprender la educación en conceptos propios); a veces necesitaremos teorías prácticas y teorías interpretativas (para orientar la intervención hacia fines socialmente prescritos o para comprender la intervención educativa en términos validados por otras disciplinas consolidadas, como la Psicología, la Sociología, etc.); y, a veces, necesitaremos teorías filosóficas (en plural) de la educación, que se centran en conocer 
las consecuencias que se derivan para la educación de una determinada concepción de vida (así se hacen las filosofías de la educación o teorías filosóficas, en plural, de la educación) y, a veces, necesitaremos teoría filosófica (en singular) de la educación que se centra en hacer análisis fenomenológico, dialéctico, crítico-hermenéutico o lingüístico de un fin en sí, estudiar la lógica interna del fin dentro del sistema conceptual de 'educación', etcétera (así se hace la filosofía de la educación o teoría filosófica, en singular, de la educación) (Tourinán, 1987 y 2008; Gargallo, 2002; Ortega, 2003; Rodríguez, 2006; Boavida y García del Dujo, 2007; Escámez, 2007; Sáez, 2007).

Desde esta perspectiva, y atendiendo al sentido que se le atribuya a la relación entre "teoría" y "educación", se puede profundizar en cuatro modos de entender la Teoría de la educación en el contexto de la investigación disciplinar, que ya había adelantado en el Cuadro 1:

1. Como Investigaciones teóricas acerca de la educación (Teorías filosóficas cosmovisionarias y teorías interpretativas de la educación, entre las que se incluye la filosofía de la educación, en singular).

2. Como Investigaciones de teoría práctica de la educación (Tecnologías derivadas o Investigación activa validada con las teorías interpretativas, para alcanzar metas socialmente valiosas).

3. Como Investigaciones teóricas de la educación o teorías sustantivas (Teoría como nivel epistemológico de análisis, distinto del nivel Tecnología y del nivel Investigación activa o Práctica).

4. Como Investigaciones de Teoría de la educación como disciplina académica sustantiva (teoría, tecnología y práctica o investigación activa de la intervención pedagógica general).

Y siguiendo esta línea de argumentación vamos a ver en las páginas siguientes cómo cada mentalidad pedagógica realiza, desde cada corriente, investigaciones teóricas en el campo de la educación que son objeto de disciplinas académicas específicas, cuya denominación singular "teoría de la educación" no significa siempre lo mismo.

\subsection{Investigaciones teóricas acerca de la educación. Las filosofías de la educación y las teorías interpretativas de la educación}

Las investigaciones teóricas acerca de la educación establecen vinculaciones entre condiciones y efectos que afectan a un acontecimiento educativo en términos de las disciplinas que lo interpretan. Las teorías filosóficas de la educación, las investigaciones específicas de la filosofía de la educación y las teorías interpretativas son investigaciones teóricas acerca de la educación, porque la educación se considera en ellas como un marco de referencia que se interpreta en términos de las disciplinas generadoras. Son el ámbito específico de las investigaciones aplicadas (Dewey, 1929; O'Connor, 1971; Hirst, 1967; Colom, 2002).

Las teorías filosóficas de la educación resuelven la educación deductivamente, desde las concepciones del mundo y de la vida. Su objetivo es la formulación explícita de los intereses de vida y la propuesta del modo de armonizar esos intereses. Su propuesta definitiva es la de establecer con qué fin se lleva a cabo la educación, o dicho de otro modo, su propuesta es el estudio normativo de los fines de vida en los que deben formarse los hombres (Touriñán, 1987, pp. 242-431; Fullat, 1979, p. 71; Brubacher, 1962). Como disciplina responde a la estructura reflejada en el Cuadro 5: 


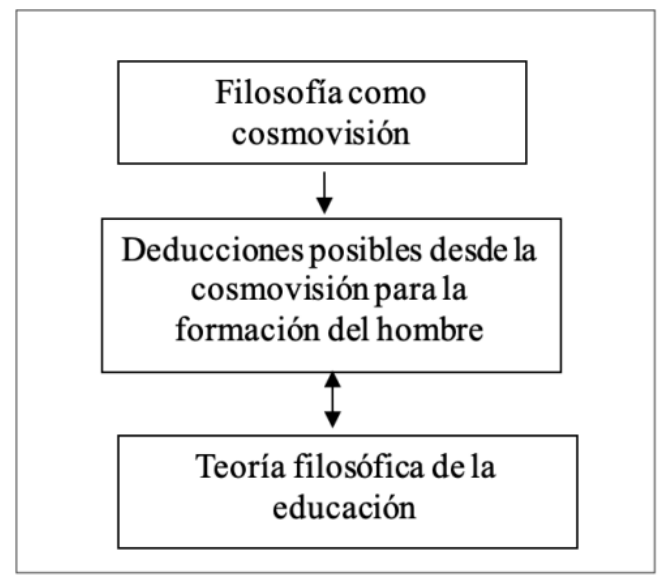

Cuadro 5: Estructura de la disciplina Teoría de la Educación como Teorías Filosóficas acerca de la educación.

Fuente: Touriñán, 2016, p. 902.

Las Teorías filosóficas de la educación constituyen una disciplina específica. Pero, si distinguimos las formas de conocimiento -racionalidad científico-tecnológica, racionalidad práxica (moral y política), racionalidad teológica, racionalidad literaria y artística, etc.)-, denominar Teoría de la Educación sólo a las filosofías de la educación es un modo impreciso de hablar, admisible en el lenguaje coloquial, pero inadecuado para un lenguaje técnico. El hecho de que gran parte de la historia del conocimiento de la educación se corresponda con la mentalidad pedagógica cosmovisionaria, no es razón suficiente para identificar la Teoría de la Educación con las concepciones de la vida deseable, la concepción personal que uno tiene de la vida o con una parte de la historia del conocimiento de la educación: aquella que corresponde a la creación y propuesta de filosofías de la educación.

La cuestión no es si existe una disciplina denominada Filosofías de la Educación o Teorías filosóficas de la Educación. La cuestión es, más precisamente, si, por el hecho de que exista una disciplina cuyo contenido se consolida desde la investigación propia de las teorías filosóficas, ya no puede haber ninguna otra disciplina que se denomine con propiedad Teoría de la Educación (Quintana, 1982). El propio desarrollo del conocimiento de la educación confirma que la consideración de la disciplina de Teoría de la Educación como la disciplina que estudia las Filosofías de la Educación sólo es comprensible en un estadio desfasado de desarrollo disciplinar de la educación. En la actualidad las Filosofías de la Educación son un campo de investigación específica, con disciplina propia y del mismo nombre (Belth, 1971; Walton, 1971; Quintanilla, 1978; Putnam, 1962, Suchodolsky, 1979; García Aretio, 1989; García Aretio, Ruiz Corbella y García Blanco, 2009; Bowen, y Hobson, 1979; Carr, 2014 y 2006; Capitán, 1979; Fermoso, 1976; Smeyers, 2010).

En el marco de las teorías interpretativas, la filosofía de la educación no se confunde con las filosofías de la educación de carácter cosmovisionario (Dewey, 1929 y 1971; Lucas, 1969; Suchodolski, 1979; Nordembo, 1979; González Álvarez, 1977, p. 20; Ibáñez Martín, 1982 y 2005; Campillo, Esteve, Ibáñez-Martín y Touriñán, 1974; Quintana, 1982; Touriñán, 1979 y 1989; Agís, 2019). En la disciplina Filosofía de la educación, en singular, la educación es un marco de referencia que se resuelve en términos de la disciplina generadora. En este caso la filosofía no es una cosmovisión, sino una disciplina lógica, analítica, crítica o metafísica y su función es dar una interpretación de la educación 
como problema lógico, lingüístico, metafísico o crítico. La Teoría de la Educación es un tratado especial de filosofía; es una filosofía aplicada, se especializa la tarea, no la disciplina; precisamente por eso puede afirmarse que como disciplina responde a la estructura reflejada en el Cuadro 6.

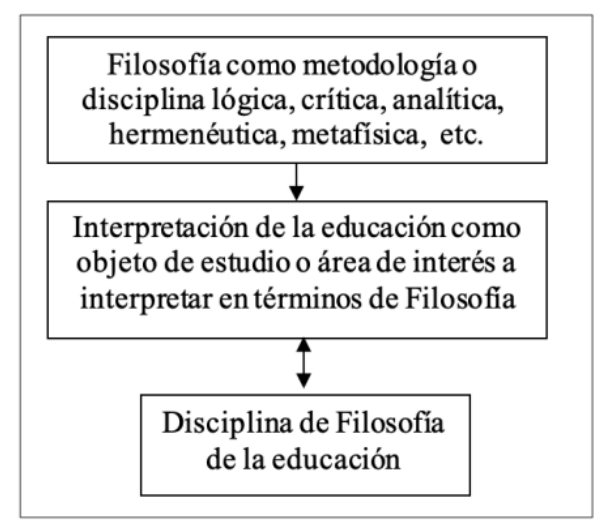

Cuadro 6: Estructura de la disciplina Teoría de la Educación como Filosofía de la educación Fuente: Touriñán, 2016, p. 881.

Como teoría interpretativa, la educación no constituye una disciplina con conceptos autóctonos que tienen significación intrínseca, sino que es una disciplina que interpreta la educación en conceptos de otras disciplinas. Como objeto de conocimiento la educación se resuelve en términos de las disciplinas generadoras que actúan como teorías interpretativas, utilizando tan sólo los principios elaborados por esas teorías interpretativas. En este caso, la educación es un ámbito de conocimiento subalternado que se resuelve en teorías interpretativas de psicología de la educación, biología de la educación, sociología de la educación, etc. La educación se interpreta en conceptos de psicología, Biología, Sociología, antropología, etcétera.

Las teorías interpretativas establecen vinculaciones entre condiciones y efectos que afectan a un acontecimiento educativo en términos de las disciplinas que lo interpretan. Las teorías interpretativas son investigaciones teóricas acerca de la educación, porque la educación se considera en ellas como un marco de referencia que se interpreta en términos de las disciplinas generadoras. Son el ámbito específico de las investigaciones aplicadas (Dewey, 1929; O'Connor, 1971; Hirst, 1967; Colom, 2002) y su modo de construir conocimiento se adapta al esquema que se presenta en el Cuadro 7.

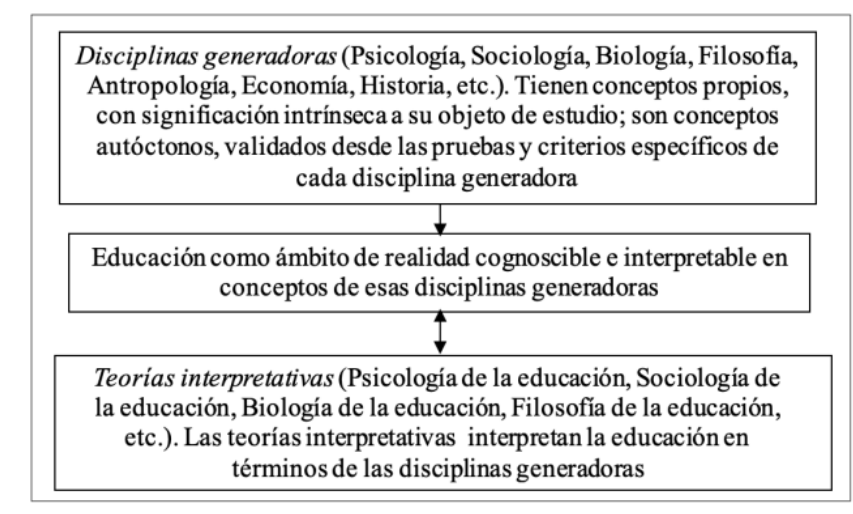

Cuadro 7: Construcción de una teoría interpretativa en educación

Fuente: Touriñán, 2008, p. 181. 
La Teoría de la Educación se identifica en este caso con las teorías interpretativas. La Teoría de la Educación se corresponde en este caso con el conjunto de teorías interpretativas o investigaciones aplicadas que explican el ámbito de realidad 'educación' en conceptos que los investigadores de cada una de esas disciplinas generadoras han creado en su propio ámbito de estudio.

Las teorías interpretativas son tratados especiales (aplicaciones) de las disciplinas generadoras. Las teorías interpretativas establecen, por tanto, vinculaciones entre condiciones y efectos de un acontecimiento educativo en términos y pruebas de las disciplinas generadoras de otros ámbitos de realidad. Son investigaciones aplicadas de las disciplinas generadoras. La Psicología, la Sociología, la Antropología, la Biología, la Economía, la Historia, etc., son disciplinas generadoras, tienen estructura teórica consolidada por la forma de conocimiento adecuada a su objeto de estudio y han desarrollado, con autonomía funcional, conceptos propios en los que puede subsumirse la actividad educativa (Ausubel, 1982, p. 25- 36; Bunge, 1985, pp. 236-239 y 1979, p. 35; Castillejo, 1987; Colom, 1982, 1986, 2001, 2002, 2005 y 2008; Dewey, 1988).

Existen tantos tipos de teorías interpretativas como disciplinas generadoras puedan aplicar sus conceptos al ámbito de educación e interpretarlo. Su estructura disciplinar se ajusta al esquema representado en el Cuadro 8.

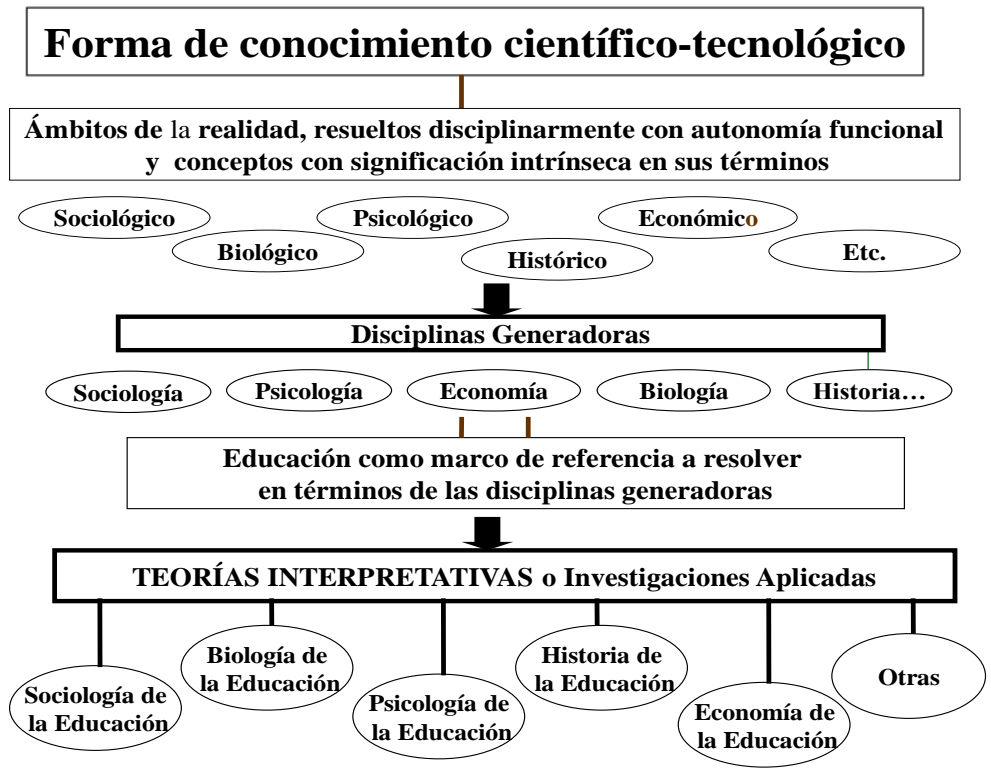

Cuadro 8: Estructura de la disciplina Teoría de la Educación como teoría interpretativa Fuente: Touriñán, 2016a, p. 882.

A los efectos de este discurso hacemos sinónimos teoría interpretativa y una acepción de la investigación aplicada. En la literatura científica, el término 'aplicada' se entiende en dos acepciones:

- a) Como aplicación de una ciencia al conocimiento de un campo (este es el sentido estricto de la teoría interpretativa como disciplina aplicada).

- b) Como aplicación de una ciencia a la acción y a la resolución de problemas prácticos o a objetivos sociales (es el sentido estricto de las aplicaciones técnicas y de las teorías prácticas). 
Ambos sentidos de investigación aplicada han venido contraponiéndose al concepto de investigación tecnológica, dando lugar así a tres categorías: investigación básica (teoría sustantiva), investigación aplicada (teoría interpretativa) e investigación tecnológica. Y desde este marco se entienden los conceptos de disciplina "general" y "aplicada": Biología general y biología aplicada, Antropología general y aplicada, Pedagogía general y aplicada, y así sucesivamente; dos conceptos que se han integrado en muy diversas ciencias tales como medicina, psicología, sociología, economía, pedagogía, etcétera, en la misma medida en que todas pueden aplicarse a otros conocimientos y a problemas prácticos.

En nuestra opinión el sentido primero (a) de investigación aplicada es epistemológicamente similar a la estructura de la investigación básica (patrones de explicación, vinculando condiciones y acontecimientos por medio de teorías).

El sentido segundo (b) de investigación aplicada tiene epistemológicamente, una estructura similar a la de la investigación tecnológica (transforma una realidad encadenando, por medio de las teorías, un proceso de reglas que permiten lograr las metas construyendo las condiciones más adecuadas).

Nuestra posición, por tanto, distingue dos grandes categorías epistemológicas: la investigación científica y la investigación tecnológica. Cada una de ellas es susceptible, a su vez, de dos estructuras.

- Investigación científica (básica y aplicada, entendida esta última en su acepción de teoría interpretativa).

- Investigación tecnológica (aplicación de una ciencia a problemas prácticos -aplicaciones técnicas y teorías prácticas- y tecnologías sustantivas o tecnologías específicas, según la corriente de conocimiento).

Ambas categorías tienen un papel específico en la práctica, que se entiende aquí como la puesta en acción de la secuencia de intervención concreta en cada caso.

Con todo, debe quedar bien claro que la mayor semejanza epistemológica a nivel de estructura, entre la teoría práctica y la investigación tecnológica, frente a la teoría interpretativa, no da pie a obviar las diferencias entre teorías prácticas y tecnologías sustantivas. Las teorías prácticas, dado que la validez de las metas no se deriva del propio proceso, sino del carácter social y moral de las mismas, conviene encuadrarlas también con propiedad en el ámbito de la racionalidad práxica. Las teorías prácticas forman parte, por la validación de los medios, de la racionalidad científico-tecnológica, y por la validación de las metas, forman parte de la racionalidad práxica.

\subsection{Investigaciones de teoría práctica de la educación. Las teorías prácticas de la educación}

Las investigaciones de teoría práctica de la educación se identifican como tecnologías derivadas; son construcciones racionales que dirigen la acción, estableciendo reglas de intervención, a partir de metas-expectativas, social y moralmente sancionadas como metas educativas, y medios validados por teorías interpretativas. Las teorías prácticas, en tanto que tecnologías derivadas, no son patrimonio exclusivo de la investigación educativa, sino de cualquier campo en el que existan expectativas sociales. En la educación existen expectativas sociales y parece innegable, por tanto, que es un campo adecuado para el desarrollo de teorías prácticas. Los partidarios de las teorías prácticas han constituido uno de los grupos más reforzados en el ámbito de la práctica educativa (Schwab, 1973; O'Connor, 1973; Broudy, 1977; Novak 1977 y 1998; Novak y Gowin, 1984; Sarramona, 2007; García 
del Dujo, 2006; Colom, 1982, 2001, 2005 y 2008; Quintanilla, 1978; Hirst, 1966 y 1973; Moore, 1980; Quintana, 1988 y 2009; García Carrasco, 1983, 1988 y 2012; García Hoz, 1970, pp. 44-50; Gottler, 1954, pp. 32 y 39-41; Henz, 1976, pp. 22-23; Hubert, 1975, pp. XIII-XVII; Nassif, 1985 y 1975, pp. 72-79; Carr y Kemmis, 1988; Álvarez, 2015; Cortés, Rodríguez y Val, 2018). La estructura disciplinar básica de una teoría práctica queda reflejada en el Cuadro 9.

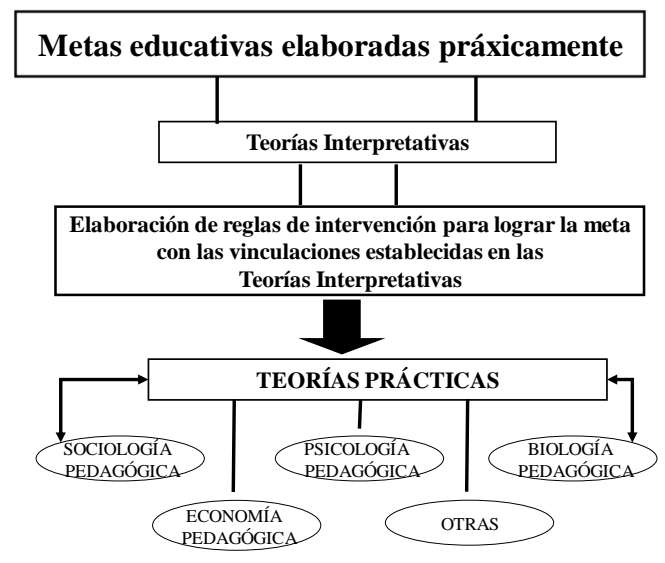

Cuadro 9: Estructura de la disciplina Teoría de la Educación como teoría práctica

Fuente: Touriñán, 2016, p. 884.

La cuestión fundamental no es, si son justificables las teorías prácticas; la cuestión básica es, más bien, si las teorías tienen que hacerse sólo como se hacen habitualmente en educación, es decir, bajo el patrón de teorías prácticas, y por tanto, como conocimiento subalternado a las teorías interpretativas (O'Connor, 1971, p. 160).

Para clarificar esta cuestión, me parece oportuno seguir una estrategia comparada. En efecto, la Biología es una disciplina científica con estructura teórica consolidada; dispone de teorías sustantivas y tecnologías específicas, elaboradas en conceptos propios de la Biología. Desde conceptos propios de la Biología, sus teorías sustantivas establecen vinculaciones entre condiciones y efectos y legitiman cambios de estado, o sea, establecen metas u objetivos intrínsecos de la Biología; por su parte, sus tecnologías específicas prescriben reglas para alcanzar esos objetivos intrínsecos con las vinculaciones establecidas en sus teorías sustantivas y, además, genera investigación activa sobre la realidad biológica.

Pero, a mayor abundamiento, si nos preguntamos cómo contribuir a la calidad educativa de la sociedad con la Biología, estamos planteando una cuestión de teoría práctica. En este caso, la Biología es un estudio autónomo que tiene sus objetivos intrínsecos; pero, también, contribuye a solucionar metas educativas desde teorías prácticas, en la misma medida que la Biología valide medios que permitan generar reglas, interpretando la educación y las metas en términos biológicos. Podemos actuar con la Biología analógicamente respecto de la educación y entender ésta como una meta social que se resuelve en términos de la Biología; construimos, así, la teoría práctica de la educación desde el patrón interpretativo de la Biología.

La cuestión que no se plantea, en este caso, es la posibilidad de que los términos educacionales tengan significación propia, autóctona, y existan objetivos intrínsecos, metas pedagógicas, además de 
expectativas sociales dirigidas al sistema educación, de manera tal que específicamente se podrían interpretar las expectativas sociales en términos de Pedagogía.

Se abre así la posibilidad de entender que no se trata de abandonar el campo de las teorías prácticas, porque la educación es un ámbito adecuado para las teorías prácticas, sino de entender que la Pedagogía, como estudio autónomo, con corpus conceptual propio de "educación", no es una teoría práctica (del mismo modo que la Biología no es una teoría práctica, aunque se utilice en ellas) y puede generar investigaciones teóricas de la educación como nivel epistemológico e investigaciones de teoría de la educación como disciplina académica sustantiva.

\subsection{Investigaciones teóricas de la educación. La teoría de la educación como nivel de análisis epistemológico, el ámbito de las teorías sustantivas de la educación}

Una disciplina con autonomía funcional como pueden serlo la Psicología, la Biología, la Sociología, la Pedagogía, etcétera, usa las formas de conocimiento adecuadas a su ámbito de conocimiento (en el caso de la Pedagogía, el ámbito de conocimiento es la educación), entendido ésta como ámbito de realidad complejo con significación intrínseca en sus términos. Precisamente por eso la Pedagogía como disciplina que tiene autónoma funcional elabora proposiciones teóricas sustantivas de la educación, proposiciones tecnológicas específicas de la educación y secuencias de intervención ajustadas en cada caso concreto a la racionalidad que mejor se adecua a la complejidad de su objeto de conocimiento.

La autonomía es funcional y no es incompatible con la existencia de relaciones de dependencia entre disciplinas. Autonomía funcional quiere decir posibilidad de concebir un campo de conocimiento que se desarrolla no como consecuencia de presiones y recomendaciones externas provenientes de otros campos dotados de estructura teórica consolidada, sino como resultado de regulaciones internas del propio campo de conocimiento, de tal manera que la teoría de ese campo quede limitada por los conceptos, hipótesis y metodologías del propio campo y no por las teorías de otros campos (Touriñán y Sáez, 2015, Touriñán, 2014 y 2016)

Las teorías sustantivas de la educación se conocen también como investigaciones de teoría de la educación como nivel de análisis epistemológico. Teoría, tecnología y práctica o investigación activa, son niveles de análisis epistemológico que se aplican a las formas de conocimiento, para dar cuenta ajustada de la complejidad de su objeto de estudio. Se diferencian entre sí, desde un punto de vista ontológico, por el aspecto o parcela del conocimiento pedagógico que les incumbe, identificado con el análisis del aspecto, parcela o sector del ámbito de conocimiento "educación" que es propio de cada disciplina sustantiva (intervención pedagógica, enseñanza, etc.) Se identifican todas ellas de manera genérica y desde un punto de vista epistemológico, por centrarse en un determinado nivel de análisis epistemológico aplicable a las formas de conocimiento: el nivel "teoría", que se distingue del nivel "tecnología” y del nivel "investigación activa o práctica" (Cuadro 10). 


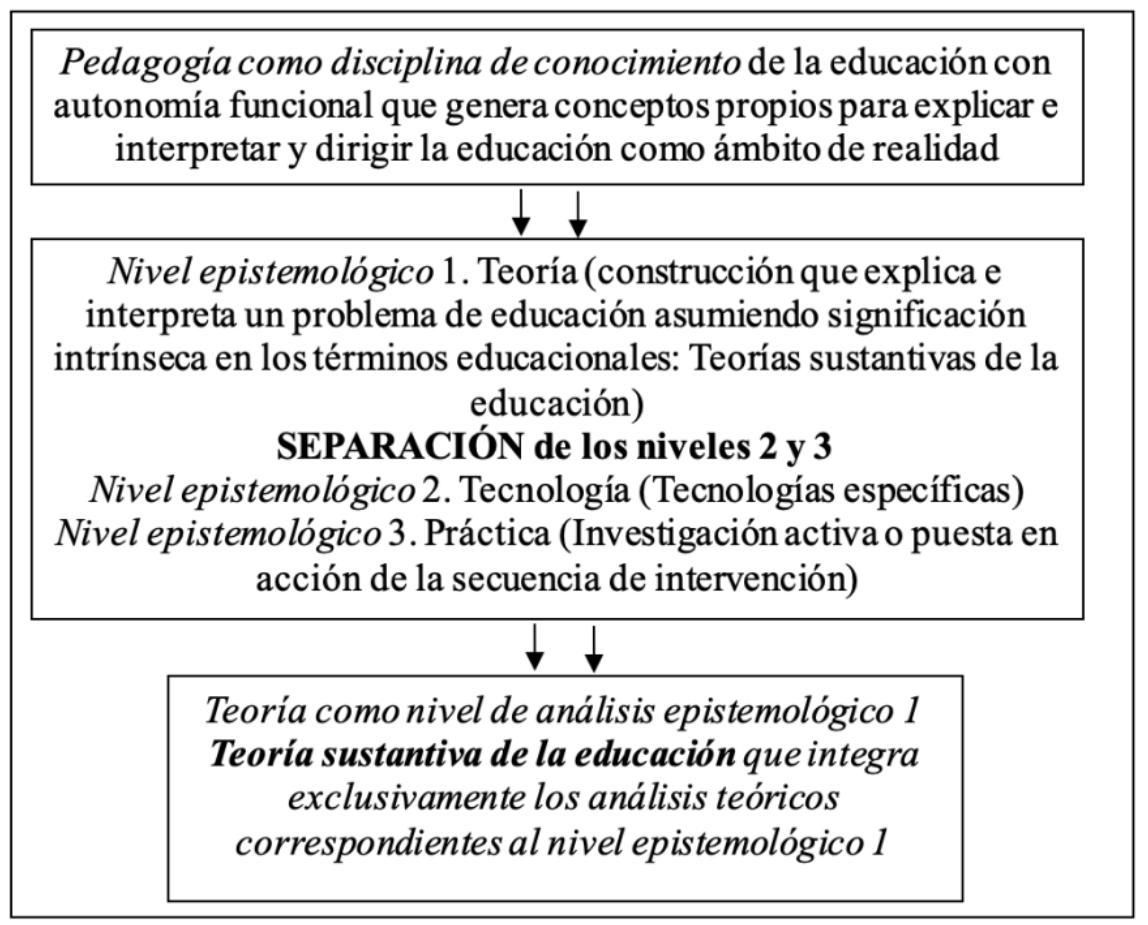

Cuadro 10: Construcción de una Teoría sustantiva en la Pedagogía

Fuente: Touriñán, 2016, p. 906.

En conjunto, constituyen el ámbito propio de la investigación básica de la Pedagogía, entendida esta como disciplina de conocimiento, con autonomía funcional (Herbart, 1805; Dilthey, 1965 -original de 1884-; Nohl, 1968 -original de 1934-; Belth, 1971; Walton, 1971; Vázquez, 1981 y 1984; Toulmin, 1972 y 2003; Touriñán, 1987; Castillejo, 1987; Colom, 2005). Las teorías sustantivas legitiman cambios de estado y orientan la acción, estableciendo vinculaciones entre condiciones y efectos de un acontecimiento educativo en conceptos con significación intrínseca al ámbito disciplinar.

Podemos decir, por tanto, que en la mentalidad pedagógica que postula la disciplina con autonomía funcional la teoría de la educación no es competencia de los especialistas de otros ámbitos, sino que en cada ámbito disciplinar hay competencia teórica, tecnológica y práctica, para los problemas del ámbito, porque la relación es de interdependencia entre los tres niveles. Desde este planteamiento es legítimo decir que la Pedagogía como disciplina del conocimiento de la educación es teoría, tecnología y práctica de la educación, o sea, que además de existir, como ya hemos visto, investigaciones aplicadas de la educación y teorías prácticas de la educación, en la Pedagogía hay investigación básica (teorías sustantivas o teoría como nivel de análisis epistemológico), tecnología específica e investigación activa, como reflejamos en el Cuadro 11. 


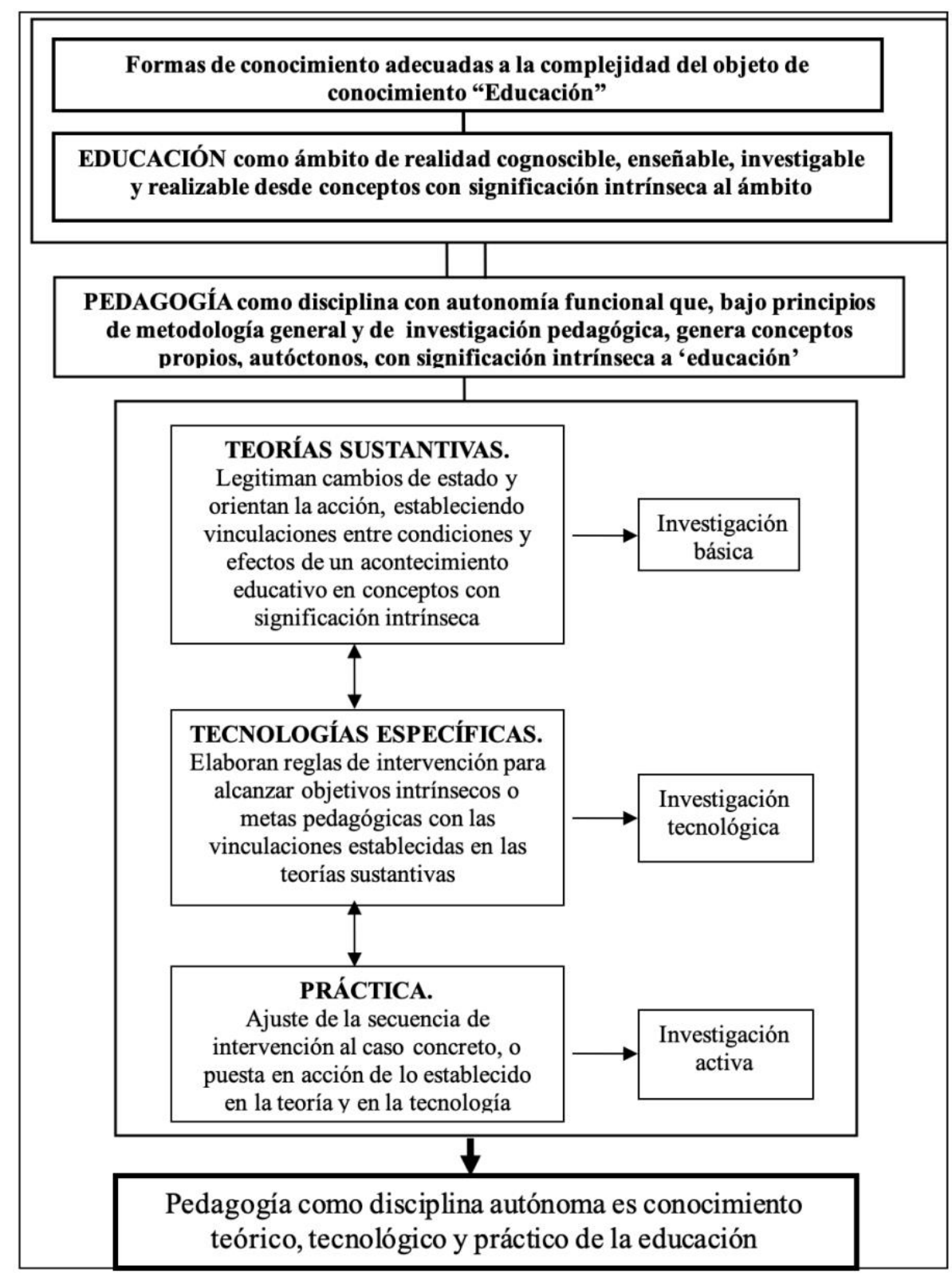

Cuadro 11: Pedagogía como disciplina con autonomía funcional

Fuente: Touriñán, 2016, p. 887.

Las investigaciones teóricas de la educación como nivel de análisis epistemológico se corresponden con las teorías sustantivas de la educación. En conjunto, constituyen el ámbito propio de la investigación básica de la Pedagogía, entendida esta como disciplina de conocimiento, con autonomía funcional.

Cómo sea esa teoría es un problema abierto en el marco de la educación entendida como ámbito de realidad con significación intrínseca en sus términos. $Y$ en este sentido, conviene recordar que con motivo del Cincuentenario de los estudios universitarios de Pedagogía, el profesor Gonzalo Vázquez escribió el artículo La pedagogía general, ¿una teoría general de la educación? Problemática actual y perspectivas de futuro y mantenía que esa teoría general "tiene el carácter de una teoría tecnológica, esto es, es una teoría que se ocupa de lo que hay que hacer para conseguir el desarrollo de los acontecimientos de un modo determinado" (Vázquez 1984, p. 29); un modo determinado que no 
niega el origen de la ciencia pedagógica, ni renuncia a los postulados de la autonomía (Vázquez, 1980 y 1981).

\subsection{Investigaciones de teoría de la educación como disciplina académica sustantiva de la Pedagogía}

Las investigaciones de Teoría de la Educación como disciplina académica sustantiva de la Pedagogía se corresponden con el desarrollo y validación de modelos, de explicación, interpretación y transformación de la intervención pedagógica general y con la aplicación de esos modelos a los problemas específicos de la disciplina. Es el campo de la intervención pedagógica general, que se predica de cualquier acto educativo fundado en el conocimiento de la educación. El campo de investigación en la disciplina de Teoría de la Educación entendida como disciplina académica sustantiva, no está constituido por todos los problemas teóricos sustantivos de la educación, sino sólo por aquellos problemas que pertenecen al ámbito de la disciplina en tanto que problemas teóricos y tecnológicos de la intervención pedagógica general, como puede verse en el esquema el Cuadro 12.

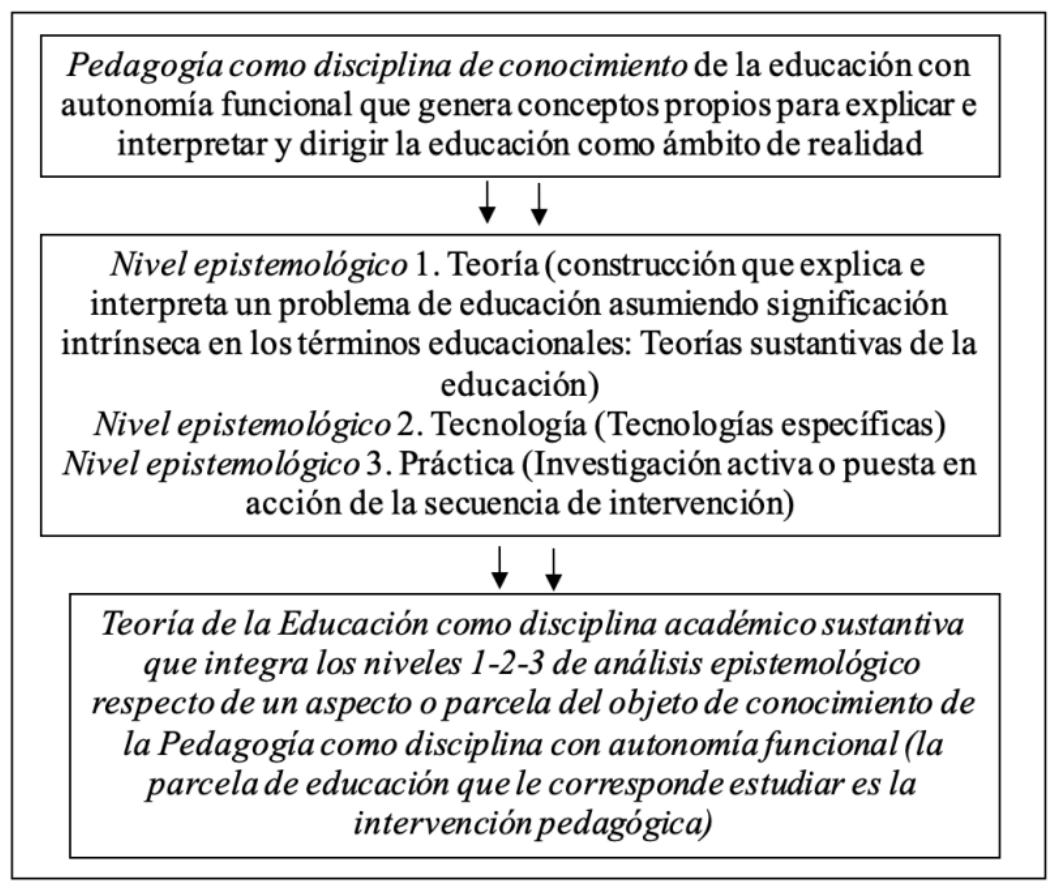

Cuadro 12: Construcción de una Teoría de la Educación como disciplina académica sustantiva en la Pedagogía

Fuente: Touriñán, 2016, p. 906.

La Teoría de la Educación como disciplina académica sustantiva de la disciplina autónoma Pedagogía se construye como todas las disciplinas académicas sustantivas, por parcelación de la disciplina autónoma que las genera; en este caso la Pedagogía. Como disciplina, y epistemológicamente, usa la forma de conocimiento que utiliza la Pedagogía y ontológicamente restringe su ámbito de estudio al aspecto, parcela o sector de la Pedagogía que le corresponde; es teoría, tecnología y práctica de la intervención pedagógica general. Se ocupa de la investigación de los elementos estructurales de la intervención pedagógica y de la construcción de ámbitos de educación y del diseño educativo derivado que se materializa en cada intervención pedagógica (Touriñán, 2017). 
Como disciplina académica sustantiva la Teoría de la Educación no es en la corriente autónoma, un nivel de análisis epistemológico aplicable a las formas de conocimiento (no es equivalente a teoría sustantiva), sino un conocimiento vinculado a un aspecto, parcela o sector de la Pedagogía que se resuelve con las formas de conocimiento adecuadas a la complejidad objetual de "educación" en los tres niveles de análisis epistemológico. El conocimiento disciplinar de un ámbito de realidad (conocimiento del ámbito o disciplina) implica la combinación de niveles epistemológicos aplicados a formas de conocimiento (criterio epistemológico) y ámbito de realidad a conocer (criterio ontológico). Las disciplinas sustantivas hacen teoría, tecnología e investigación activa del sector de educación que estudian, con la racionalidad que se ajusta a la complejidad de su objeto de estudio. El criterio disciplinar no es sólo epistemológico, es también ontológico, de parcela de realidad a estudiar y conocer desde la disciplina (Cuadro 13).

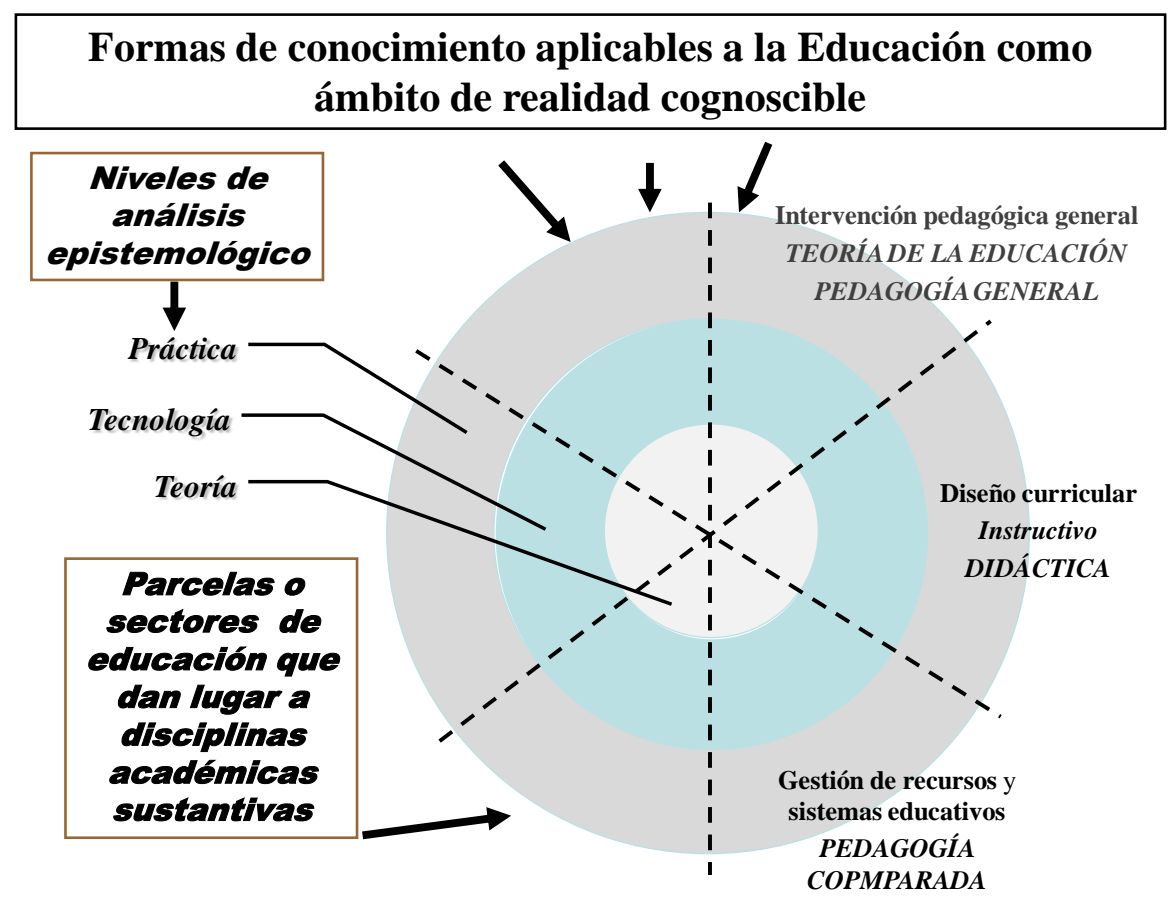

Cuadro 13: Integración de componentes de disciplinas académicas sustantivas

Fuente: Touriñán, 2016, p 892.

Las investigaciones de teoría de la educación como disciplina académica sustantiva ponen el énfasis en la investigación de y en la disciplina, es decir, estamos centrados en los problemas de racionalidad de la disciplina, es decir, en el desarrollo y validación de modelos de explicación, interpretación y transformación de los problemas propios de la disciplina como campo de conocimiento (investigación de) y en la aplicación de esos modelos a los problemas específicos del campo (investigación en). La tarea es, por una parte, el sentido, es decir, la justificación de la racionalidad de la disciplina (investigación de) y, por otra (investigación en), el desarrollo y consolidación de los conocimientos investigados en la disciplina, a partir de la concepción de la disciplina.

La investigación en la disciplina de teoría de la educación depende de la investigación de la disciplina. Es el propio modo de concebir la disciplina el que condiciona el crecimiento simple intensivo, extensivo e intrínseco- del campo disciplinar. Como ya hemos visto, el cambio de supuestos 
en el conocimiento de la educación hace variar el modo de concebir la disciplina y esto explica que los problemas investigados y los modos de investigarlos desde una concepción puedan ser revisados en parte, subsumidos, suplementados o considerados como no pertinentes desde otra concepción.

Las investigaciones de Teoría de la Educación como disciplina académica sustantiva se corresponden con el desarrollo y validación de modelos, de explicación, interpretación y transformación de la intervención pedagógica general y con la aplicación de esos modelos a los problemas específicos de la parcela de educación que se constituye en su objeto de estudio. El campo de investigación en la disciplina de Teoría de la Educación entendida como disciplina académica sustantiva, no está constituido por todos los problemas teóricos de la educación, sino sólo por aquellos problemas que pertenecen al ámbito de la disciplina en tanto que problemas teóricos, tecnológicos y prácticos de la intervención pedagógica general (elementos estructurales de la intervención).

\subsection{La Teoría de la Educación como disciplina académica sustantiva es parcela de la disciplina Pedagogía}

La Teoría de la educación se construye en este caso como todas las disciplinas académicas sustantivas, por parcelación del ámbito de conocimiento de la disciplina autónoma que la genera; en este caso la Pedagogía. Como disciplina, y epistemológicamente, usa la forma de conocimiento que utiliza la Pedagogía y ontológicamente restringe su tarea al aspecto, parcela o sector del ámbito de realidad "educación" que le incumbe.

Como disciplina académica sustantiva la Teoría de la Educación no es en la corriente autónoma, un nivel de análisis epistemológico aplicable a las formas de conocimiento (no es equivalente a teoría sustantiva), sino un conocimiento vinculado a un aspecto, parcela o sector de la Pedagogía que se resuelve con las formas de conocimiento adecuadas a la complejidad objetual de "educación" en los tres niveles de análisis epistemológico. El conocimiento disciplinar de un ámbito de realidad (conocimiento del ámbito o disciplina) implica la combinación de niveles epistemológicos aplicados a formas de conocimiento (criterio epistemológico) y ámbito de realidad a conocer (criterio ontológico). Las disciplinas sustantivas hacen teoría, tecnología e investigación activa del sector de educación que estudian, con la racionalidad que se ajusta a la complejidad de su objeto de estudio. El criterio disciplinar no es sólo epistemológico, es también ontológico, de parcela de realidad a estudiar y conocer desde la disciplina, tal como hemos reflejado en los Cuadros 11, 12 y 13.

Todo ámbito cuyo conocimiento es identificado epistemológicamente por la forma de conocimiento, que a su vez es identificado ontológicamente como ámbito de realidad con significación intrínseca en sus términos, constituye una disciplina autónoma, como la Psicología, la Historia, la Pedagogía, la Economía, etc. Estas disciplinas se subdividen a su vez en subdisciplinas, ámbitos parciales de investigación o disciplinas académicas sustantivas. Las disciplinas académicas sustantivas son académicas, porque forman parte del programa académico de la carrera y son sustantivas, porque la pedagogía es lo sustantivo que las identifica y construyen su diferencia dentro de la parcela pedagógica que les incumbe, elaborando las teorías sustantivas, las tecnologías específicas y las investigaciones activas que les son pertinentes a su sector del conocimiento del ámbito de realidad "educación".

Desde los postulados del conocimiento de la educación en la corriente autónoma, puede decirse que la Pedagogía como disciplina autónoma se configura en diversas disciplinas sustantivas, según el aspecto, parcela o sector del ámbito de conocimiento "educación" que estudian. La Pedagogía 
general (Teoría de la educación), la organización escolar, la orientación educativa, la didáctica, el diagnóstico, etcétera, constituyen un conjunto representativo de las disciplinas académicas que son sustantivamente pedagógicas (Vázquez, 1984, p. 24; Castillejo, 1985, p. 53; Touriñán, 1987 y 2020b; Quintana 1988).

Cada una de estas disciplinas combina niveles de análisis epistemológico aplicado a la forma de conocimiento que se ajusta a la complejidad de su objeto de estudio y aspecto o parcela o sector del ámbito de realidad "educación" que van a conocer. En tanto que la Pedagogía como disciplina autónoma formula y resuelve problemas teóricos sustantivos de la educación y problemas tecnológicos y prácticos específicos de la educación, parece correcto afirmar que cada una de las disciplinas académicas sustantivamente pedagógicas implica a su vez problemas teóricos, tecnológicos y prácticos del aspecto o del sector o parcela de la educación que estudia disciplinarmente. El hecho de que en todas las disciplinas académicas sustantivas de la Pedagogía no estén desarrollados por igual sus problemas teóricos, tecnológicos y prácticos obedece más bien a contingencias particulares de su propio desarrollo como disciplina que a una real ausencia de problemas teóricos o tecnológicos en las cuestiones de la educación que estudia.

\subsubsection{Teoría como nivel de análisis y teoría como disciplina académica sustantiva no deben confundirse}

Teniendo en cuenta las disciplinas académicas sustantivamente pedagógicas que hoy se cultivan en la ciencia de la educación, la Teoría de la Educación como teoría sustantiva (nivel teórico de análisis epistemológico) no debe confundirse con la Teoría de la educación como disciplina académica sustantiva. Existen problemas teóricos sustantivos de la educación, problemas tecnológicos específicos y problemas prácticos de la educación en otras disciplinas académicas sustantivamente pedagógicas; esas disciplinas hacen teoría, tecnología e investigación activa del sector de educación que estudian. El criterio disciplinar no es sólo epistemológico, es también ontológico, de parcela de realidad a estudiar y conocer desde la disciplina, por eso es necesario mantener la distinción clara entre forma de conocimiento y niveles de análisis aplicables (criterio epistemológico), ámbito de conocimiento y de realidad a conocer (criterio ontológico) y conocimiento del ámbito (ciencia o disciplina construida).

Cada disciplina académica sustantiva tiene sus problemas teóricos, tecnológicos y prácticos correspondientes a su parcela disciplinar. Se identifica ontológica y epistemológicamente, como ya hemos visto, dentro de la Pedagogía. La teoría de la educación como teoría sustantiva o nivel de análisis epistemológico no es lo mismo que la teoría de la educación como disciplina académica sustantiva y su identificación implica negar, como hemos dicho, la relación de interdependencia entre los niveles teoría, tecnología y práctica.

Por consiguiente, si, a pesar de haber entendido el criterio disciplinar (que implica criterio ontológico y epistemológico) elaboramos, para la Teoría de la Educación como disciplina académica sustantiva, un programa de teoría entendida sólo como teoría sustantiva, entramos en solapamiento con los programas de las otras disciplinas académicas sustantivas, porque incluiríamos en nuestro programa de teoría problemas teóricos sustantivos de la parcela o sector del ámbito de conocimiento "educación" que corresponde a otras disciplinas académicas sustantivas de la Pedagogía, negando la relación de interdependencia entre teoría, tecnología y práctica en el ámbito de realidad a estudiar. Dada esa interdependencia, la diferencia en las disciplinas sustantivas no es solo el nivel de análisis 
epistemológico y la forma de conocimiento, sino también de parcela de realidad a conocer. Las disciplinas académicas sustantivas de la disciplina autónoma Pedagogía (conocimiento del ámbito) son parcelas del conocimiento pedagógico; la parcela que le corresponde en cada caso, identificado por la aplicación de los niveles epistemológicos de teoría, tecnología y práctica a las formas de conocimiento que mejor se ajustan a la complejidad del aspecto, parcela o sector del ámbito de realidad "educación" que van a conocer (ámbito de conocimiento) desde la disciplina.

Con las diversas matizaciones que puedan darse dentro de los partidarios de la corriente autónoma, se reconoce que la Teoría de la Educación, como disciplina académica sustantiva, es una parte de la Pedagogía como disciplina autónoma y se ocupa del conocimiento teórico, tecnológico y práctico de la intervención pedagógica general.

\subsubsection{La Teoría de la Educación como disciplina académica sustantiva es Pedagogía general}

Llegados a este punto del discurso acerca de la racionalidad de la disciplina parece obvio que, desde un punto de vista estrictamente lógico, no habría inconveniente en que la denominación de una disciplina fuera la de "Pedagogía General", porque la pedagogía general es ciencia de la educación en general, según la tradición más depurada (Quintana 1978 y 1988, p. 26; Capitán Díaz, 1979; Marín, 1983; Vázquez, 1981; Medina, 1992; Basabe y otros, 1983). Pero también encontramos en la tradición razones a favor de la denominación "Teoría de la educación", pues no debemos olvidar que el conocimiento autónomo de la educación evoluciona en sus orígenes desde la "Pedagogía General derivada del fin de la educación" de Herbart hasta la "Teoría de la Educación de validez general" de Nohl (Touriñán, 1987).

El conocimiento de la educación ha evolucionado y su crecimiento nos permite hablar hoy con propiedad y sin confusión, distinguiendo entre Pedagogía y Educación, entre conocimiento del ámbito (Pedagogía, en este caso) y el ámbito de conocimiento (educación).

Siguiendo la misma línea de argumentación, debe recordarse que determinar la denominación de disciplinas por el ámbito de conocimiento (educación, en nuestro caso) es adecuada, según el uso común, para disciplinas de investigaciones aplicadas a otros campos y teorías interpretativas; se dice Sociología del trabajo, Psicología de la medicina, de la educación, etcétera y se dice también como aplicaciones de la Pedagogía, pedagogía del trabajo (laboral), de la familia, de adultos (gerontológica), del sistema carcelario (carcelaria) u otras. Así mismo, las disciplinas académicas sustantivas, suelen denominarse por el conocimiento del ámbito respetando la identificación nominal con la disciplina científica que representan (Pedagogía, en nuestro caso); se dice, en este sentido, Pedagogía general, comparada, de la enseñanza (Didáctica), diferencial o de orientación educativa, etc.

Si no olvidamos que las disciplinas sustantivas se constituyen por parcelación del ámbito de conocimiento de la disciplina autónoma de la que derivan -en este caso Pedagogía- parece estar del lado del sentido común la propuesta de denominación de Pedagogía General para la disciplina académica sustantiva, lo cual, dicho sea de paso, es coherente a su vez con el uso de la denominación de "pedagogía" laboral, "pedagogía" familiar, etcétera, para las disciplinas aplicadas que nacen de la disciplina matriz.

Y así las cosas, no sólo la distinción entre ámbito de conocimiento y conocimiento del ámbito, sino también la distinción entre teorías interpretativas y teorías sustantivas, disciplinas aplicadas y disciplinas académicas sustantivas refuerzan la tendencia a favor de la denominación de Pedagogía 
General. De este modo, la voz "Teoría de la educación" sería voz propia de las teorías interpretativas y de las teorías prácticas y de las investigaciones teóricas de la educación identificadas con la teoría como teoría sustantiva o primer nivel epistemológico de análisis.

Ahora bien, no se deben olvidar los vicios y errores conceptuales que prosperaron históricamente al amparo del término "Pedagogía General" y que favorecieron su polisemia y, peor aún, su ambigüedad semántica, hasta el extremo de que se considerase pertinente la sustitución de esa denominación por otra ajena a esas confrontaciones. La tendencia es utilizar el término "Teoría" en la disciplina por esas diversas razones entre las que se encuentra el prestigio debido al éxito de los modos científicos de explicación y comprensión (Gowin, 1963 y 1972; O'Connor, 1971; Campillo, Esteve, Ibáñez y Touriñán, 1974; Escolano, 1978 y 1979; Vázquez, 1984; García Carrasco, 1988 y 1984; García Carrasco y García del Dujo, 1996 y 2001; Touriñán, 1987; Tusquets, 1972; Nassif, 1985; Belth, 1971; Trilla, 1987; Castillejo y otros, 1994; Colom, 1983, 1987, 2002 y 2006; Bowen y Hobson, 1979; Quintana, 1988; García Aretio, 1989; Puig, 1986 y 2003; García Aretio, Ruiz Corbella, y García Blanco, 2009; Gargallo, 2002; Ortega, 2003; Escámez, 2007; Sáez, 2007; Sarramona, 2007; Naval, 2008; Aznar, Gargallo, Garfella y Cánovas, 2010; Jover y Thoilliez, 2010; Gil Cantero, 2011; García del Dujo, 2006; Boavida y García del Dujo, 2007; Rabazas, 2014; Biesta, Allan y Edwards, 2014; Sección de Ciencias de la Educación, 1984; Rodríguez, 2006; Sáez Alonso, 2007 y 2016; ).

Desde la perspectiva de la Teoría de la Educación-Pedagogía general como disciplina académica sustantiva, conviene resaltar en este momento de la argumentación que, en las disciplinas sustantivas, no hay una que es el tronco común. No hay un tronco común, sino que cada disciplina tiene sus problemas, sus métodos de trabajo etc., según cuál sea su objeto de estudio o ámbito de conocimiento dentro de la disciplina científica. Y esto es lo que hay que tener presente cuando se une el calificativo "general" a una disciplina sustantiva. En el caso de Pedagogía, cuando hablamos de disciplinas sustantivas, la pedagogía general no es el tronco común general (la disciplina) que se aplica, especializando la tarea, a las demás disciplinas sustantivas (Didáctica, Pedagogía comparada, Orientación educativa, etcétera, que dejarían de ser sustantivas para convertirse en disciplinas aplicadas.), sino que lo que se especializa en el caso de las disciplinas sustantivas es la propia disciplina. Todas son Pedagogía; todas tienen problemas teóricos, tecnológicos y prácticos de su ámbito; todas son disciplinas sustantivas, pero la pedagogía general no resuelve el problema de la Didáctica, ni es su tronco común, porque "intervención pedagógica" y "enseñanza" son conceptos con problemas teóricos, tecnológicos y prácticos específicos y porque las disciplinas sustantivas se diferencian por la parcela del ámbito de conocimiento que les incumbe (en este caso intervención pedagógica y enseñanza, respectivamente), elaborando sus conceptos específicos, sus contenidos propios y sus pruebas desde sus análisis teóricos, tecnológicos y prácticos. Cada una de estas disciplinas sustantivas puede aplicarse a otros ámbitos, especializando la tarea, y precisamente por eso podemos hablar con propiedad de disciplinas aplicadas como pedagogía laboral y didáctica de las ciencias sociales, por ejemplo.

Para algunos autores, las dificultades lógicas de ese tronco común han forzado de manera muy directa la transformación de la disciplina Pedagogía general en la asignatura "Introducción a las ciencias de la educación" o en la asignatura de "Introducción a la Pedagogía" (Debesse y Mialaret, 1972; Mialaret, 1977; Sanvisens, 1987; Ferrández y Sarramona, 1979). Esta tendencia, que pudo consolidar en momentos y de manera concreta esas asignaturas en muy diversos planes de estudios, sustituyendo a la disciplina Pedagogía general, no es razón de hecho suficiente para confundir el 
razonamiento epistemológico, porque la "Introducción a las ciencias de la educación" o la "Introducción a la Pedagogía" que son dos asignaturas posibles, sólo son manifestaciones, a lo sumo, de pedagogía "en" general. Lo cierto es que desde el punto de vista epistemológico y ontológico, si se iguala Pedagogía "general" con Pedagogía "en general", estamos simplificando de manera errónea el sentido de general en las disciplinas sustantivas. En la pedagogía "en" general o en la "Introducción" a la pedagogía no hay criterio disciplinar -ontológico y epistemológico-, sino criterio pragmático de asignatura: ¿qué puedo enseñar a principiantes para que se inicien en el conocimiento singular de una disciplina científica determinada?

Se sigue, por tanto, que definir la Teoría de la educación como disciplina académica sustantiva no es un problema de Pedagogía "en" general -de introducción a la pedagogía o de introducción a las ciencias de la educación- que podría existir como asignatura de un plan de estudios), ni de Pedagogía general teórica (nivel epistemológico "teoría" frente a nivel tecnología y nivel "practica"), ni un problema de Pedagogía general tronco común frente a las pedagogías aplicadas (Pedagogía del trabajo, de la familia, de la educación general, de la educación profesional, de la educación de adultos, de lo social, $\mathrm{u}$ otras, que especializan la tarea y van a existir siempre que avance la posibilidad de aplicación de la disciplina matriz), o frente a otras disciplinas sustantivas especializadas (didáctica, organización, comparada, etcétera, que especializan la ciencia matriz hasta vaciarla), sino un problema de delimitación como disciplina académica sustantiva, junto a otras disciplinas sustantivas del mismo rango dentro de la Pedagogía como disciplina científica y que tienen, por tanto, cada una de ellas, su ámbito de conocimiento y su conocimiento del ámbito, definidos ontológica y epistemológicamente en relación con la disciplina científica matriz (Pedagogía).

Por una parte, hay que buscar un sentido propio a la disciplina académica sustantiva, que no confunda nivel epistemológico y nivel ontológico en la disciplina sustantiva -pues cada disciplina académica sustantiva plantea problemas teóricos, tecnológicos y prácticos de la parcela de conocimiento de la educación que le incumbe y desarrolla conceptos con significación intrínseca a su ámbito de estudio- $y$, por otra parte, hay que aceptar la complejidad conceptual de la pedagogía como disciplina de conocimiento de la educación que, debe desarrollar conceptos con significación intrínseca a su ámbito de estudio y conocimiento, de conceptos autóctonos que permiten establecer relaciones con capacidad de resolución de problemas para la vinculación teoría-practica.

Desde la perspectiva de la corriente autónoma de la Pedagogía, eso implica siempre sentido tecnoaxiológico en la disciplina (Touriñán, 1997, 2012b y 2015a):

- La educación siempre es educación en valores que marcan el carácter y el sentido de la educación

- La educación siempre se ejerce por medio de agentes en un área determinada de intervención (áreas de experiencia )

- La educación siempre implica intervención técnica de más o menos nivel; implica adoptar decisiones técnicas en procesos específicos en un determinado ámbito de educación (intervención pedagógica, enseñanza, sistema educativo); es decir, se adoptan decisiones técnicas (elección de fines y medios dentro de un ámbito de conocimiento, con fundamento en el conocimiento verdadero de ese ámbito).

Hablamos en este sentido de Pedagogía tecnoaxiológica. El conocimiento específico para la función pedagógica es el conocimiento que hace posible la elección técnica, no sólo porque es una elección 
dentro de un ámbito determinado de necesidades, sino también porque el criterio de decisión se funda estrictamente en el conocimiento verdadero del funcionamiento del ámbito en el que se actúa (en este caso, la educación como ámbito de conocimiento que tiene en la Pedagogía la manifestación genuina del conocimiento de ese ámbito, es decir, de los fines y medios derivados del propio sistema en el que se trabaja).

Pero, además, tenemos que hablar, con mayor sentido de aproximación a la intervención concreta y específica, de Pedagogía mesoaxiológica, porque la intervención requiere conocimiento pedagógico al nivel suficiente para hacer efectiva la acción. Es decir, hay que dominar el conocimiento pedagógico para legitimar pedagógicamente la intervención, porque hay que convertir el área en y desde la que se interviene en instrumento y meta de la educación y eso exige construirla como experiencia axiológica de valor educativo en cada intervención. La pedagogía es mesoaxiológica, porque transforma la experiencia que usamos al intervenir en ámbito de educación. Es importante mantener esta precisión e identificación como ámbito de educación, porque su defensa y fundamentación contribuye a formar criterio en los profesionales de la educación acerca del valor educativo de un área cultural y su posibilidad como conocimiento pedagógico. Tiene sentido afirmar, como ya hemos dicho, que no es lo mismo "saber Historia", "enseñar Historia" y "educar con la Historia"; sólo en el último caso la Historia se convierte en ámbito de educación y, por tanto, en instrumento y meta de la intervención pedagógica (Touriñán, 2012b, 2013, 2014, 2015a y 2016). La Pedagogía es Mesoaxiológica, porque cada área de experiencia cultural tiene que ser valorada como educación y construida como "ámbito de educación", un concepto que tiene significación propia desde el conocimiento de la educación y está vinculado al significado de la educación, a los procesos de intervención, a las dimensiones generales de intervención y a las áreas de experiencia y a las formas de expresión que mejor se ajustan a cada área en cada acepción técnica de ámbito (Touriñán y Longueira, 2018).

En perspectiva mesoaxiológica, transformar información en conocimiento y este conocimiento en educación exige entender la relación que hay entre el conocimiento de la educación y el concepto de educación, a fin de adquirir competencia para construir el ámbito de educación, hacer el diseño educativo y generar la intervención, de manera que la función de educar sea vista también como competencia técnica que se ejerce en cada caso con mentalidad pedagógica específica y con mirada pedagógica especializada. La perspectiva mesoaxiológica se resume, conceptualmente hablando, en los siguientes postulados (Touriñán, 2020a):

- Conocer, enseñar y educar tienen distinto significado el conocimiento de áreas culturales no es el conocimiento de la educación. El conocimiento de la educación fundamenta el nexo entre mentalidad pedagógica específica mirada pedagógica especializada y acción educativa concreta controlada y programada para formar la condición individual social histórica y de especie de cada educando

- Transformamos información en conocimiento y conocimiento en educación, ajustándonos al significado de educación, utilizando la actividad común del educando sin la cual es imposible educar y buscando la concordancia entre valores y sentimientos en el paso del conocimiento a la acción

- La función pedagógica es técnica, no política, aunque la educación sea un asunto de interés político; la decisión en Pedagogía, que es conocimiento de la educación, es tecnoaxiológica y mesoaxiológica 
- En perspectiva mesoaxiológica construimos ámbitos de educación hacemos el diseño educativo pertinente y generamos la intervención pedagógica atendiendo a principios de educación y a principios de intervención que se justifican con el conocimiento de la educación

- Usamos la actividad común de manera controlada para lograr actividad educada y educar la actividad con mentalidad pedagógica específica y mirada pedagógica especializada desde los elementos estructurales de la intervención, porque sin la actividad común es imposible educar y gracias a ella se hace posible que el educando sea agente actor y cada vez mejor agente autor de su propios proyectos y actos.

Construir ámbitos de educación, generar diseño educativo, orientar formativamente buscando la concordancia valores-sentimientos en cada intervención, es competencia general del pedagogo. Y esa competencia general puede aplicarse a muy diversos ámbitos, familia, escuela, ciudad educadora, cárceles, trabajo, etc. Ese es el futuro de las profesiones de la educación vinculadas a la Pedagogía como conocimiento de la educación.

En cuanto al nombre, desde el punto de vista institucional y administrativo el debate está decantado actualmente hacia la denominación "Teoría de la Educación" para la disciplina académica sustantiva (Ortega, 2003; García del Dujo, 2006; Boavida y García del Dujo, 2007; Escámez, 2007; Sáez, 2007; Sarramona, 2007; Naval, 2008; Jover y Thoilliez, 2010; Gil Cantero, 20011; Ferraz, Amaro, Folgado y Lopes, 2011, Martínez y otros, 2016; Altarejos, 2003; SI(e)TE. Educación, 2013, 2016 y 2018; Biesta, Allan y Edwards, 2014; Rabazas, 2014; García Aretio, Ruiz Corbella, y García Blanco, 2009; Conant, 1963; Department of State of the United States of America, 1945; Gil Cantero, 2017; Martínez y otros, 2016, Touriñán, 1995). Y en este sentido, nuestra propuesta personal dentro de la corriente autónoma es que, sin renunciar al nombre de teoría de la educación para la disciplina académica sustantiva, la teoría de la educación como disciplina académica sustantiva es, en sentido estrictamente lógico, Pedagogía general, es decir, es disciplinarmente una parcela sustantiva de la Pedagogía que tiene epistemológicamente la forma de conocimiento de la Pedagogía y que se identifica, ontológicamente, con un aspecto, parcela o sector del ámbito de realidad "educación" a conocer, el de la intervención pedagógica general (Touriñán, 2016):

a) Es Pedagogía, porque la Pedagogía como ciencia de la educación es conocimiento teórico, tecnológico y práctico de la educación, entendida ésta como un ámbito de realidad y de conocimiento con significación intrínseca en sus términos. La Teoría de la Educación tiene epistemológicamente la forma de conocimiento de la Pedagogía y se somete a los mismos principios metodológicos y de investigación pedagógica que la disciplina autónoma.

b) Es general, porque el término general expresa el aspecto o parcela del conocimiento pedagógico que le incumbe y la distingue de las otras disciplinas académicas sustantivas. General se entiende en sentido lógico como lo que se predica del conocimiento pedagógico con independencia de las consideraciones diferenciales, que es, en este caso, la intervención pedagógica general, las dimensiones generales de intervención y los elementos estructurales de la intervención pedagógica. La Teoría de la Educación es disciplinarmente parcela sustantiva de la Pedagogía; una parcela 
identificada ontológicamente con la intervención pedagógica general, que es la parcela o sector del ámbito de realidad "educación" que tiene que conocer.

Así las cosas, la presencia de problemas teóricos sustantivos y tecnológicos específicos, pero sectoriales, en otras disciplinas académicas sustantivas de la ciencia de la educación es compatible con la existencia de la Teoría de la Educación como disciplina académica sustantiva de la Pedagogía que se ocupa de los problemas de explicación, interpretación y transformación de la intervención pedagógica general, o lo que es lo mismo, que se ocupa de la teoría, de la tecnología y de la práctica de la intervención pedagógica general.

Como disciplina académica sustantiva de la Pedagogía, la definición de Teoría de la educación como Pedagogía general, en el sentido que acabamos de expresar: tiene rigor lógico, distingue formas de conocimiento (racionalidades), ámbito de conocimiento (educación) y conocimiento del ámbito (pedagogía), distingue criterio epistemológico, ontológico y disciplinar; como disciplina académica sustantiva, distingue teorías interpretativas, teorías prácticas y teorías sustantivas, integra teoría, tecnología e investigación activa en la disciplina respecto de su propio ámbito de conocimiento y respeta el sentido de la tradición y la denominación propia de las disciplinas sustantivas, que se identifican por el nombre adjetivado de la disciplina autónoma de la que proceden, o por un nombre propio singular y distinto (pedagogía general y didáctica, por ejemplo) .

La Teoría de la Educación, como disciplina académica sustantiva, tiene un papel específico en la investigación pedagógica y posee un dominio disciplinar específico (conocimiento del ámbito) en el que se abordan los problemas de educación con sentido de autonomía funcional desde la perspectiva de la intervención pedagógica general; es una disciplina sustantiva que aplica los niveles epistemológicos a las formas de conocimiento que mejor se ajustan a la complejidad objetual de educación en su parcela de estudio: la intervención pedagógica general (ámbito de conocimiento). Para nosotros, la investigación pedagógica sustenta a la educación y la hace susceptible de estudio desde cada ámbito disciplinar, utilizando y desarrollando el ámbito de realidad de la educación como objeto y como meta de su quehacer.

Salvando las diferencias que se dan, por razones pragmáticas de tipo institucional y administrativo, en los programas concretos de asignaturas de los planes de estudios de los diversos distritos universitarios, hoy se hace hincapié en la necesidad de potenciar cuatro áreas de investigación con el objeto, no sólo de consolidar el campo de la Teoría de la Educación como disciplina académica sustantiva (Pedagogía General), sino también de acentuar la potencia formativa de la disciplina sustantiva de Teoría de la Educación en el currículum de los profesionales de la Educación. Estas cuatro áreas son (Touriñán, 2017):

a) El conocimiento de la educación, es decir, la educación como objeto de conocimiento y la construcción del conocimiento pedagógico que permite generar la mentalidad pedagógica, aplicar principios metodológicos y generar principios de investigación pedagógica, ajustados al significado del objeto de conocimiento "educación".

b) El estudio de la función pedagógica como función de los profesionales de la educación, que permite caracterizarla como función especializada y específica, distinta de otras funciones tales como la función médica, la función psicológica, sociológica, antropológica, etc. 
c) Los procesos de intervención pedagógica y la relación educativa, es decir, el desarrollo de pautas de explicación, comprensión y transformación de la intervención, que permiten construir principios de educación y principios de intervención pedagógica, atendiendo, en un caso, al carácter y al sentido de la educación, y en otro, a los elementos estructurales de la intervención.

d) El estudio de las dimensiones generales de intervención pedagógica y la construcción de ámbitos de educación.

Desde esta perspectiva de aproximación al problema, la Teoría de la Educación, tiene el reto de permanecer abierta a la investigación para favorecer su desarrollo como teoría sustantiva (nivel de análisis) y como disciplina académica sustantiva, bien sea como investigación acerca de la educación como ámbito de realidad, bien sea como investigación del conocimiento de la educación. Y esto afecta a la disciplina como disciplina a enseñar, a investigar y de investigación; y por tanto, a la resolución de problemas atendiendo a la relación teoría-práctica, que es el núcleo de la mentalidad pedagógica.

El logro de mentalidad pedagógica específica y de mirada pedagógica especializada es el camino de realización de la competencia pedagógica. El pedagogo está orientado a la fundamentación del conocimiento necesario para la construcción ámbitos de educación desde la actividad común interna del educando, atendiendo a los elementos estructurales de la intervención: tiene que saber cuál es la capacidad de resolución de problemas y cuál es su visión crítica de su método y de sus actos, ni más ni menos que cualquier otro profesional de nivel universitario.

Construir ámbitos de educación, generar diseño educativo, orientar formativamente buscando la concordancia valores-sentimientos en cada intervención, es competencia general del pedagogo. Y esa competencia general puede aplicarse a muy diversos ámbitos, familia, escuela, ciudad educadora, cárceles, trabajo, etc. Ese es el futuro de las profesiones de la educación vinculadas a la Pedagogía como conocimiento de la educación y a la Pedagogía general (Teoría de la educación como disciplina académica sustantiva) cuyo objeto de estudio es la intervención pedagógica.

\section{Consideraciones finales: la teoría de la educación está consolidada, es aplicable y es una herramienta necesaria para dominar la intervención pedagógica.}

A modo de conclusión puede decirse que la educación -sea artística, física, política, social, sanitaria, etcétera, cualquiera que sea el ámbito o parcela de intervención- es un ámbito de realidad susceptible de ser conocido de diversas formas. Ámbito de realidad es cualquier cosa, física, mental o cultural que sea cognoscible, investigable, enseñable o realizable, con independencia de que esté pensando ahora en ella. La racionalidad científico-tecnológica, la racionalidad práxica, la racionalidad teológica y la racionalidad literaria y artística son dimensiones del conocimiento con peculiaridades propias que las hacen acreedoras del nombre formas de conocimiento. Son dimensiones del conocimiento, porque la extensión del criterio de conocimiento es en cada caso distinta. Son formas de conocimiento, porque cada una tiene sus conceptos distintivos; esos conceptos surgen en diferentes tareas y sus relaciones determinan las proposiciones significativas que pueden ser hechas en cada forma. Ni hablamos de la bondad moral de triángulo, ni de la expresión literaria del carbono. Cada forma de conocimiento tiene sus peculiares modos de prueba acerca de la verdad y validez de sus proposiciones (Touriñán, 1987).

Cualquier ámbito de realidad que sea cognoscible, investigable y enseñable, se convierte por principio de significado en ámbito de conocimiento. Es fundamental distinguir entre "ámbito de conocimiento" y "conocimiento del ámbito", entre Educación y Pedagogía, para saber de qué hablamos 
en cada caso, pues las Carreras estudian el conocimiento del ámbito y las Facultades se definen por el conocimiento del ámbito, no por el ámbito de conocimiento. Es posible parcelar el conocimiento de la educación en disciplinas y es posible parcelar la educación en ámbitos. El crecimiento del conocimiento de la educación puede generar nuevas disciplinas y nuevos ámbitos. En la carrera de Pedagogía aprendemos a descubrir, inventar e innovar en educación como actividad, como ámbito de realidad y como ámbito de conocimiento, perfeccionando nuestro conocimiento del ámbito. Las disciplinas tienen un lugar específico en este proceso, bien sea como investigación a cerca de la educación como ámbito de realidad, bien sea como investigación del conocimiento de la educación. Y esto afecta a la disciplina como disciplina a enseñar, a investigar y de investigación.

En la investigación científica hablamos de investigación básica y de investigación aplicada (teorías sustantivas y teorías interpretativas). En la investigación tecnológica hablamos de aplicaciones técnicas y de teorías prácticas. Y, además, en la investigación científica hablamos de investigación activa o práctica. Es conocimiento común que en la forma de conocimiento científico-tecnológica hay tres niveles epistemológicos de análisis: teoría, tecnología y práctica o investigación activa. Por eso en investigación hablamos respecto de la educación de pluralidad de investigaciones: investigaciones teóricas acerca de la educación, investigaciones de teoría práctica, investigaciones teóricas de la educación e investigaciones de teoría de la educación como disciplina.

Las investigaciones generan conocimiento sobre un ámbito de realidad (educación, en nuestro caso) y ese conocimiento sistematizado se organiza en disciplinas científicas, que son sistematizaciones de conocimiento de un ámbito bajo criterios ontológico y epistemológico (ámbito de realidad + forma de conocimiento + autonomía funcional metodológica = disciplina científica). Las disciplinas científicas, con el conocimiento sistematizado, permiten, a quien consigue dominarlo, focalizar la realidad de estudio, generando mentalidad específica y mirada especializada desde esa disciplina en los profesionales.

La Pedagogía como disciplina científica es teoría, tecnología y práctica o investigación activa de la educación. La pedagogía como carrera es el conjunto de materias que se estudian dentro de un plan de estudios con el objetivo de obtener un título (en España, debe estar ajustado a directrices de carácter oficial y validez nacional y habilita para el ejercicio profesional en funciones pedagógicas de acuerdo con las disposiciones vigentes). En la carrera de pedagogía no solo hay Pedagogía como disciplina. La Pedagogía como disciplina se desagrega en disciplinas académicas sustantivas y en asignaturas del plan de estudios y, además de disciplinas y asignaturas de Pedagogía, en la carrera de pedagogía se estudian otras materias formativas que interpretan la educación desde sus propios desarrollos científicos.

A veces necesitaremos teorías sustantivas de la educación (para explicar y comprender la educación en conceptos propios); a veces necesitaremos teorías prácticas y teorías interpretativas (para orientar la intervención hacia fines socialmente prescritos o para comprender la intervención educativa en términos validados por otras disciplinas consolidadas, como la Psicología, la Sociología, etc.); a veces, necesitaremos teorías filosóficas (en plural) de la educación, que se centran en conocer las consecuencias que se derivan para la educación de una determinada concepción de vida (así se hacen las filosofías de la educación o teorías filosóficas, en plural, de la educación) y, a veces, necesitaremos teoría filosófica (en singular) de la educación que se centra en hacer análisis fenomenológico, dialéctico, crítico-hermenéutico o lingüístico de un fin en sí, estudiar la lógica interna del fin dentro del sistema conceptual de 'educación', etcétera (así se hace la filosofía de la educación o teoría filosófica, en 
singular, de la educación). En las disciplinas académicas sustantivas y en las asignaturas de planes de estudios están integradas por razones pragmáticas y por razones epistemológicas, según el caso, esas teorías. Las asignaturas pueden mezclar pedagogía general, filosofía de la educación y teorías filosóficas y teorías interpretativas de la educación y teorías prácticas, por razones pragmáticas, pero no deben conculcar las razones epistemológicas de la disciplina sustantiva en ningún caso. Y esto afecta, como ya he dicho a la calidad de los planes de estudios, a las carrearas que se diseñan, a la disciplina científica misma y a las facultades que las albergan.

La educación como ámbito de realidad es susceptible de ser conocida de diversas formas y cada una de ellas se aplica a la obtención del mejor conocimiento de la educación que es posible. La Pedagogía, como disciplina, es una de esas formas de obtener conocimiento de la educación: avanzar en el desarrollo de principios de educación y de intervención pedagógica requiere asumir un compromiso claro con los principios de metodología e investigación para ir más allá de la contemplación de la intervención desde criterios nominales y de finalidad. Y no tener esto en cuenta da lugar a la perdida de significación en el conocimiento de la educación que proporciona la disciplina Pedagogía.

Las disciplinas generadoras son las que, bajo criterio ontológico y epistemológico, generan conceptos propios, autóctonos, de la parcela de realidad que estudian con autonomía funcional (Forma de conocimiento+ámbito de realidad a conocer+autonomía funcional metodológica). Una disciplina que tiene conceptos propios puede aplicarse a la interpretación de otros ámbitos de realidad siempre que esos ámbitos se ajusten a esos conceptos en alguna medida. De este modo la disciplina generadora se convierte en teoría interpretativa del ámbito en el que se aplica, porque lo interpreta desde los conceptos de la disciplina generadora. Desde esta perspectiva de aproximación, existen preocupaciones y estudios acerca de la educación que se resuelven en términos de disciplinas generadoras tales como la Psicología, la Sociología, la Biología, etc. En este caso, la educación es un ámbito de conocimiento subalternado que se resuelve en teorías interpretativas de psicología de la educación, biología de la educación, sociología de la educación, etcétera. Pero desde la misma perspectiva, los conceptos propios, autóctonos, de la disciplina pedagogía pueden utilizarse para interpretar ámbitos en los que la educación es el contexto de interpretación y así la pedagogía es generadora de disciplinas aplicadas como la pedagogía laboral, la pedagogía familiar, la pedagogía ambiental, la pedagogía social, la pedagogía carcelaria, etc.

Hay pedagogía aplicada, porque hay Pedagogía, pero, además, como dice Ortega y Gasset, toda ciencia particular solo tiene "jurisdicción subalterna sobre su propio vocabulario. La verdad de sus conceptos es relativa al punto de vista particular que la constituye, y vale en el horizonte que ese punto de vista crea y acota" (Ortega y Gasset, 1976, p. 20). Precisamente por eso podemos avanzar en el desarrollo conceptual de un ámbito de manera intrínseca, sin limitarlo como campo nuevo solo a significado subalterno. Y, así las cosas, hay, por ejemplo, Psicología y Psicología social, y hay también Pedagogía y Pedagogía social.

A favor del conocimiento subalternado de la educación, es plausible afirmar que en determinados momentos desconociéramos la significación intrínseca de los conceptos del ámbito de la educación. Pero, en su contra, es de sentido común reconocer que, no es suficiente concebir la Pedagogía como una disciplina de conocimiento subalternada, porque necesariamente la complejidad del proceso educativo nos fuerza a buscar significación intrínseca a su sistema conceptual. 
Existen preocupaciones y estudios acerca de la educación que se resuelven en términos de disciplinas generadoras (con conceptos aplicables a educación y la interpretan desde esos conceptos), tales como la Psicología, la Sociología, la Biología, etc. La educación puede ser interpretada en términos de motivación y comportamiento, en términos de salud y vida, en términos de relaciones sociales, etc. En estos casos, la educación es un ámbito de realidad a estudiar que se resuelve en teorías interpretativas o investigaciones aplicadas, hablamos en este caso de psicología de la educación, biología de la educación, sociología de la educación, etc.

La existencia de disciplinas aplicadas al lado de disciplinas científicas generadoras ha dado lugar a la diferenciación entre disciplina general y aplicada. Es obvio que bajo esa diferencia se han construido diversas disciplinas aplicadas o teorías interpretativas en otros ámbitos científicos, porque tienen conceptos propios que pueden aplicarse a la interpretación de otros ámbitos de realidad siempre que esos ámbitos se ajusten a esos conceptos en alguna medida. Así, se habla de sociología general y aplicada, de economía general y aplicada, de biología general y aplicada; se habla de Psicología, de Medicina, de Antropología, de Pedagogía y de las demás disciplinas científicas como disciplinas generadoras. Pero, en cada caso concreto de existencia de disciplina general y aplicada, estamos asumiendo, en palabras de González Álvarez, que las disciplinas aplicadas especializan la tarea, no la disciplina (González Álvarez, 1977).

La psicología de la educación, la psicología del trabajo, la sociología de la educación, la pedagogía laboral, la pedagogía familiar, la pedagogía social, etcétera, especializan la tarea, no la disciplina; son y aplican Sociología, Psicología, Pedagogía, etcétera, a ámbitos distintos, que son susceptibles de interpretación en términos de relación social, comportamiento y motivación, de intervención pedagógica, etcétera, según cuál sea la disciplina generadora de la interpretación.

En este sentido, se dice que la pedagogía laboral, la pedagogía familiar y otras disciplina aplicadas de la Pedagogía especializan la tarea, no la disciplina Pedagogía, que sigue siendo la misma que aplica los conceptos creados por la Pedagogía a la interpretación de cada uno de esos ámbitos en los que se aplican.

En el caso de las investigaciones aplicadas, la prueba depende de los conceptos propios de la disciplina generadora (Psicología, Biología, Sociología, Pedagogía, Antropología, etc.), pues son esos conceptos los que interpretan el ámbito aplicado.

Pero en el caso de disciplinas científicas con autonomía funcional, cada disciplina depende de sus propias pruebas. Desde la perspectiva de la Pedagogía como disciplina con autonomía funcional que genera conceptos propios con significación intrínseca al ámbito de estudio, respecto de la educación, puede decirse que pedagógicamente probado no es lo mismo que psicológicamente probado, porque los criterios de significado de educación en Pedagogía no son criterios de psicología, ni el significado de los conceptos de educación se reducen a términos de la psicología, aunque estos puedan utilizarse para interpretar la educación. Y esto se predica también de las disciplinas académicas sustantivas creadas por parcelación de cada disciplina generadora.

Por consiguiente, cuando hablamos de disciplinas sustantivas como Psicología general, diagnostico psicológico, psicología evolutiva (todas disciplinas derivadas de la parcelación, con criterio ontológico y epistemológico, de la disciplina generadora de Psicología, no de la aplicación de la psicología a otro ámbito de realidad cognoscible e interpretable en conceptos propios de la psicología), por pensar en una rama próxima, la cuestión no es que se especialice la tarea, aplicándose a otro ámbito o conjunto de problemas (psicología de la educación, del arte, del trabajo, etc.), sino 
que, dentro de la Psicología, se especializa la disciplina misma. Las disciplinas aplicadas especializan la tarea, porque la tarea es siempre interpretar otro ámbito en términos de Psicología, Sociología etc., pero en las disciplinas sustantivas se especializa la disciplina científica misma, porque cada una genera sus conceptos distintivos y modos de prueba sobre una parcela de la disciplina científica matriz (psicología, sociología, pedagogía u otras).

Se sigue, por tanto, que, definir la disciplina académica sustantiva, no es un problema de hacer pedagogías aplicadas o de aplicar la disciplina a otros ámbitos interpretables desde ellas, sino, más bien, un problema previo, de parcelación de la disciplina matriz Pedagogía. Existen pedagogías aplicadas (Pedagogía del trabajo, de la familia, de la educación general, de la educación profesional, de la educación de adultos, de lo social, u otras) y existen didácticas aplicadas o didácticas específicas o didácticas especiales, que especializan la tarea. Las disciplinas aplicadas van a existir siempre que avance la posibilidad de aplicación de la disciplina matriz. El problema de la disciplina académica sustantiva es de delimitación junto a otras disciplinas sustantivas del mismo rango dentro de la ciencia matriz y que tienen todas ellas, por tanto, su ámbito de conocimiento y su conocimiento del ámbito, definidos ontológica y epistemológicamente en relación con la parcela de disciplina científica matriz que les corresponde (Touriñán, 2016).

Cada disciplina sustantiva tiene sus problemas y sus métodos de trabajo, según cuál sea su objeto de estudio o ámbito de conocimiento dentro de la parcela que le corresponde de la disciplina científica matriz. Y esto es lo que hay que tener presente cuando se une el calificativo "general" a una disciplina sustantiva. En el caso de Pedagogía, cuando hablamos de disciplinas sustantivas, como la pedagogía general, la didáctica o la pedagogía comparada, queremos decir que todas son Pedagogía; todas tienen problemas teóricos, tecnológicos y prácticos de su ámbito; todas son disciplinas sustantivas, ajustadas a criterio ontológico y epistemológico de la Pedagogía, pero la pedagogía general no resuelve el problema de la Didáctica o el problema de la pedagogía comparada porque "intervención pedagógica", "enseñanza" y "sistema educativo" son conceptos singulares dentro del ámbito de realidad "educación" con problemas teóricos, tecnológicos y prácticos específicos y porque las disciplinas sustantivas se diferencian por la parcela del ámbito de conocimiento que les incumbe (en este caso intervención pedagógica, enseñanza y sistema educativo, respectivamente), elaborando sus conceptos específicos, sus contenidos propios y sus pruebas desde sus análisis teóricos, tecnológicos y prácticos (Tourinán, 2017).

Cada una de estas disciplinas sustantivas puede aplicarse a otros ámbitos, especializando la tarea, y precisamente por eso podemos hablar con propiedad de disciplinas aplicadas como pedagogía del trabajo, pedagogía social, pedagogía escolar, y de didácticas especiales o aplicadas como la didáctica de las ciencias sociales, y la didáctica de las matemáticas, por ejemplo. La pedagogía como disciplina y sus disciplinas académicas sustantivas derivadas por parcelación del objeto "educación" son disciplinas generadoras de conceptos propios, autóctonos, que pueden ser aplicados a otros ámbitos para interpretarlos. Y por eso tenemos pedagogía laboral, gerontológica, carcelaria, social, familiar, etc. (Touriñán, 2020b).

Y si esto es así, se sigue que lo importante es, en nuestro caso, ir desde la Pedagogía General a las Pedagogías aplicadas, porque muy diversos ámbitos de conocimiento pueden ser interpretados como disciplinas aplicadas en términos de la disciplina generadora. Es un hecho que hay pedagogía familiar, laboral, social, ambiental, carcelaria, gerontológica, de las artes, de la literatura, etc. La clave, desde la pedagogía aplicada, es transformar el ámbito de conocimiento, interpretándolo en términos 
de Pedagogía, para, de ese modo, construir el ámbito de educación, hacer el diseño educativo y generar la intervención que materializa el contenido de la expresión "educar con" (Touriñán, 2017).

La Pedagogía del futuro, como disciplina, depende en buena medida de su capacidad de generar conceptos que sean aplicables a los ámbitos de realidad que podemos interpretar desde la educación. La pedagogía tiene que ser cada vez más "aplicada"; tiene que ser capaz de interpretar problemas y dar solución a problemas reales de la vida ordinaria desde las ideas de formación y de intervención pedagógica. La pedagogía será por supuesto, pedagogía escolar, pero será necesariamente por espacio ocupacional específico pedagogía gerontológica, familiar, social, ambiental, laboral, carcelaria, no formal, etcétera. La pedagogía del futuro serán necesariamente las pedagogías aplicadas.

Estoy convencido de que, como disciplina, la Pedagogía del futuro es la pedagogía aplicada y por medio de su consistencia epistemológica le damos a la Pedagogía el lugar que le corresponde y preservamos su relación con la calidad de la educación, pues hacemos que sirva para educar reforzando su capacidad de resolución de problemas.

También estoy convencido de que, como carrera, el futuro de la Pedagogía está vinculado a la necesidad social de calidad de la educación. La calidad de educación es, como hemos visto, una necesidad social y se configura como un objetivo posible y necesario. La respuesta educativa afecta a la realidad interna y externa del educando en cada circunstancia y de acuerdo con las oportunidades, y dado que cualquier respuesta no es igualmente valiosa ni ajustada al significado de educación, inexorablemente tenemos que hacer frente a problemas de valorar la calidad en cada acción educativa. Y todo eso exige una función pedagógica específica y especializada que no se logra sin la Pedagogía. Valorar cada medio como educativo es la condición propia de la pedagogía y hace que la perspectiva de la pedagogía sea mesoaxiológica (comprender el valor del medio valorado educativamente).

Se trata de desarrollar la perspectiva Mesoaxiológica de la Pedagogía (valorar áreas de experiencia cultural como ámbitos de educación) y de su aplicación a un área de experiencia cultural concreta. El logro de mentalidad pedagógica específica y de mirada pedagógica especializada es el camino de realización de la competencia pedagógica. El pedagogo está orientado a la fundamentación del conocimiento necesario para la construcción ámbitos de educación desde la actividad común interna del educando, atendiendo a los elementos estructurales de la intervención: tiene que saber cuál es la capacidad de resolución de problemas y cuál es su visión crítica de su método y de sus actos, ni más ni menos que cualquier otro profesional de nivel universitario (Touriñán, 2018d, 2019c y 2019e; Touriñán, Rodríguez y Longueira, 2019; Morin, 1975 y 2000, pp. 2834; Lakatos y Musgrave 1981, pp. 327-336; Black, 1969; Altarejos, 2010; Gil Cantero, 2018; SI(e)TE, 2020; William, 2008; Kroman, 1997).

Construir ámbitos de educación, generar diseño educativo, orientar formativamente buscando la concordancia valores-sentimientos en cada intervención, es competencia general del pedagogo. Y esa competencia general puede aplicarse a muy diversos ámbitos, familia, escuela, ciudad educadora, cárceles, trabajo, etc. Ese es el futuro de las profesiones de la educación vinculadas a la Pedagogía como conocimiento de la educación y eso no se logra sin Teoría de la educación como disciplina académica sustantiva cuyo objeto es el conocimiento teórico, tecnológico y práctico de la intervención pedagógica. Por medio del dominio de la teoría de la educación como disciplina logramos competencia para construir ámbitos de educación, hacer el diseño educativo pertinente y generar la intervención pedagógica derivada, que es siempre acción intencional en orden a realizar fines y 
medios que se justifican con fundamento en el conocimiento verdadero de la educación (de ese conocimiento verdadero forma parte, específica y necesariamente, la teoría de la educación como disciplina académica sustantiva).

Hay futuro de la pedagogía; hay pedagogía del futuro y hay competencia pedagógica. Y cualquier programa de formación en competencias pedagógicas, que se precie como programa específico y especializado ha de tener en cuenta lo que aquí hemos dicho para entender y asumir el lugar de la teoría de la educación como concepto, como asignatura, como disciplina y como investigación y su potencial como generadora de pedagogía aplicada.

\section{Referencias}

Agis, M. (2019). Anatomia do pensar. O discurso filosófico e a súa interpetación. Vigo: Galaxia.

Álvarez, C. (2015). Teoría frente a práctica educativa: Algunos problemas y propuestas de solución. Perfiles Educativos, 37 (148), 172-190, https://doi.org/10.1016/j.pe.2015.11.014.

Altarejos, F. (2010). Subjetividad y educación. Pamplona: EUNSA.

Altarejos, F.; Rodríguez, A. y Fonttrodona, J. (2003). Retos educativos de la globalización. Hacia una sociedad solidaria. Pamplona: Eunsa.

Ausubel, D. P. (1982). Psicología educativa. Un punto de vista cognoscitivo. México: Trillas, $4^{\mathrm{a}}$ reimp. (Fecha de edición original, 1968).

Avanzini, G. (1977). La Pedagogía del siglo XX. Madrid: Narcea.

Aznar, P.; Gargallo, B.; Garfella, P. y Cánovas, P. (2010). La educación en el pensamiento y la acción. Teoría y praxis. Valencia: Tirant lo Blanch.

Basabe, J. y otros (1983). Estudios sobre epistemología y pedagogía. Madrid: Anaya.

Belth, M. (1971). La educación como disciplina científica. Buenos Aire: El Ateneo.

Berliner, D. (1986). In Pursuit of the Expert Pedagogue. Educational Researcher, 15 (7), 5-13.

Berliner, D. (2002). Educational Research: The Hardest Science of All. Educational Researcher, 31 (8), $18-20$.

Biesta, G.; Allan, J. y Edwards, R. (Eds.) (2014). Making a Difference in Theory: The Theory Question in Education and the Education Question in Theory. Londres/Nueva York: Routledge.

Black, M. (1969). El laberinto del lenguaje. Venezuela: Monte Ávila.

Boavida, J. y García del Dujo, A. (2007). Teoría da Educaçao. Contributos Ibéricos. Coimbra: Imprenta da Universidade de Coimbra.

Bowen, J. y Hobson, P. R. (1979). Teorías de la educación. México: Limusa.

Broudy, H. S. (1977). Types of Knowledge and Purpose of Education, en R. C. Anderson y otros, Schooling and the Adquisition of Knowledge. Nueva Jersey: Laurence, Erlbaum Associates, pp.117.

Brubacher, J. S. (1962). Modern Philosophies of Education. New York: McGraw-Hill.

Bunge, M. (1975). Teoría y realidad. Barcelona: Ariel, $2^{\mathrm{a}} \mathrm{ed}$.

Bunge, M. (1981). La investigación científica. Su estrategia y su filosofía. Barcelona: Ariel, $6^{\underline{a}}$ ed.

Bunge, M. (1985). Treatise on Basic Philosophy. Vol. 7. Part. II. Hollan: Reidel, Dordrecht.

Campillo, J.; Esteve, J. M.; Ibáñez-Martín, J. A. y Touriñán, J. M. (1974). Teoría de la educación (Filosofía de la educación). Madrid: UNED.

Capitán, A. (1979). Teoría de la educación. Zaragoza: Edelvives.

Carr, W. (2006). Education without Theory. British Journal of Educational Studies, 534 (2), 136-159. 
Carr, D. (2014). Diverse Senses and Six Conceptions of Education. Revista española de pedagogía, 72 (258), 219-230.

Carr, W. y Kemmis, S. (1988). Teoría crítica de la enseñanza. La investigación-acción en la formación del profesorado. Barcelona: Martínez Roca.

Castillejo, J. L. (1985). Sugerencias para una teoría de la ciencia pedagógica, en P. Aznar y otros, Conceptos y propuestas (II). Teoría de la educación. Valencia: Nau Llibres, pp. 45-56.

Castillejo, J. L. (1987). Pedagogía tecnológica. Barcelona: CEAC.

Castillejo, J. L. y Colom, A. J. (1987). Pedagogía Sistémica. Barcelona: Narcea.

Caudo, M. ${ }^{a}$ V. di (2013). La ciencia pedagógica: construcciones, disputas, desafíos. Sophia, (14), 3350.

Coham, W. (1998). Filosofía de la educación. Algunas perspectivas actuales. Aula, 141-151.

Colom, A. J. (1982). Teoría y metateoría de la educación. Un enfoque a la luz de la teoría general de sistemas. México: Trillas.

Colom, A. J. (1986). Pensamiento tecnológico y Teoría de la Educación, en la Obra Conjunta, Tecnología y Educación. Barcelona: CEAC, pp. 3-30.

Colom, A. J. (2002). La (de) construcción del conocimiento pedagógico. Nuevas perspectivas en la teoría de la educación. Barcelona: Paidós.

Colom, A. J. (2005). De la debilitat teórica de l'educació. Barcelona: Institut d'estudis cataláns.

Colom, A. J. (2006). La teoría de la educación en su doble dimensionalidad: como teoría acerca de la realidad y como teoría acerca del saber educativo. Revista Portuguesa de Pedagogía, (40-1), 143163.

Colom, A. J. (2008). Per a una pedagogía del laberint. Palma: Univeristat de les Illes Balears.

Colom, A, J. (2018). Apuntes sobre la institucionalización de la Pedagogía en España, en Grupo SI(e)TE. Educación, La Pedagogía, hoy. Santiago de Compostela: Andavira, cap. 1.

Conant, J. B. (1963). The Education of American Teachers. New York: McGraw-Hill.

Cortés, A.; Rodríguez, A.; Val, S. (Coords.) (2018). Estrategias transformadoras para la educación. Una visión para el siglo XXI. Madrid: Pirámide.

Davis, W. K. (1987). Educational Research in the Professions: Paradigms, Peer Review and Promise. Professions Education Research Notes, 9 (1), 4-9.

Debesse, M. y Mialaret, G. (1972). Introducción a la pedagogía. Tratado de ciencias pedagógicas. Barcelona: Oikos-Tau. (1 $1^{\underline{a}}$ ed., en francés, 1971).

Department of State of the United States of America (1945). The General Education in a Free Society. Report of the Harvard Committee. Cambridge (MA): Harvard Univ. Press.

Dewey, J. (1929). La ciencia de la educación. Buenos Aires: Losada.

Dewey, J. (1971). Democracia y educación. Buenos Aires: Losada, 7ª̣ ed.

Dewey, J. (1998). Cómo pensamos. Nueva exposición de la relación entre pensamiento reflexivo y proceso educativo. Barcelona: Paidós.

Dilthey, W. (1965). Fundamentos de un sistema de pedagogía. Buenos Aires: Losada, $8^{\mathrm{a}}$ ed. (fecha de edición original alemana, 1884).

Escámez, J. (2007). Las aportaciones de la Teoría a la Educación. Revista Española de Pedagogía, 65 (237), 217-235.

Escolano, A. (1979). Los estudios de ciencias de la educación: curriculum y profesiones. Salamanca: ICE de la Universidad de Salamanca. 
Escolano, A (1978). Las Ciencias de la Educación. Reflexiones sobre algunos problemas epistemológicos, en A. Escolano y otros, Epistemología y Educación. Salamanca: Sígueme, pp. 9-11 y 15-26.

Fermoso, P. (1976). Teoría de la educación. Madrid: Agulló.

Fullat, O. (1979). Filosofías de la educación. Barcelona: CEAC. (Edición ampliada de 1992, Filosofías de la Educación. Paideia. Barcelona: CEAC).

García Aretio, L. (1989). La educación. Teorías y conceptos. Madrid: Paraninfo.

García Aretio, L.; Ruiz Corbella, M. y García Blanco, M. (2009). Claves para la educación. Actores, agentes y escenarios en la sociedad actual. Madrid: Narcea.

García Carrasco, J. (1983). La ciencia de la educación. Pedagogos ¿para qué? Madrid: Santillana.

García Carrasco, J. (Coord.) (1984). Teoría de la educación, en A. Escolano (Ed.), Diccionario de Ciencias de la Educación. Madrid: Anaya.

García Carrasco, J. (1988). Apuntes de Teoría de la Educación. Salamanca: Secretaría de publicaciones de la Universidad de Salamanca.

García Carrasco, J. y García del Dujo, A. (1996). Teoría de la educación I. Educación y acción pedagógica. Salamanca: Ediciones Universidad de Salamanca.

García Carrasco, J. y García del Dujo, A. (2001). Teoría de la educación II. Procesos primarios de formación del pensamiento y la acción. Salamanca: Universidad de Salamanca.

García Carrasco, J. (2012). Diagnóstico: tristeza; tratamiento: alimentar preguntas vigorosas, en F. Gil y D. Reyero (Coords.), Homenaje a J. A. Ibáñez-Martín. Madrid: Biblioteca Online, pp. 103-127. García del Dujo, A (2006). (Coord.). Teoria da educaçao. Modos de facer e pensar hoje. Revista portuguesa de pedagogía, (40), 2 Vols. Universidade de Coimbra.

García Hoz, V. (1970). Principios de Pedagogía sistemática. Madrid: Rialp, 5ª ed. (1ª ed.de 1960).

Gargallo, B. (2002). La Teoría de la Educación. Objeto, enfoques y contenidos. Teoría de la Educación. Revista Interuniversitaria, (14), 19-46.

Gil Cantero, F. (2011). “Educación con teoría”. Revisión pedagógica de las relaciones entre la teoría y la práctica educativa. Teoría de la educación. Revista Interuniversitaria, 23 (1), 19-43.

Gil Cantero, F. (2018). Escenarios y razones del antipedagogismo actual. Teoría de la Educación. Revista Interuniversitaria, 30 (1), 29-51.

Gil Cantero, F. (Ed.) (2017). Educación y desarrollo humano. Madrid: Revista española de Pedagogía.

Gil Cantero, F.; Lorenzo, M. y Trilla, J. (2019). La teoría en la formación de profesionales de la educación. Ponencia $1^{\underline{a}}$ del XXXVIII Seminario Interuniversitario de Teoría de la Educación: Formar para transformar: cambio social y profesiones educativas. Málaga, noviembre 2019. Disponible en http://eventos.uma.es/27579/detail/xxxviii-seminario-interuniversitario-deteoria-de-la-educacion.html (conslultado 3-2-2020).

González Álvarez, A. (1977). Filosofía de la educación. Buenos Aires: Troquel.

Göttler, J. (1967). Pedagogía Sistemática. Barcelona: Herder, $4^{a}$ ed.

Gowin, D. B. (1963).Can Educational Theory Guide Practice? Educational Theory, 13 (1), 6-12.

Gowin, D. B. (1972). Is Educational Research Distinctive?, en L. G. Thomas (Ed.) Philosophical Redirection of Educational Research. 71 Yearbook of the National Society for the Study of Education. Parte 3, 1. Chicago: University of Chicago Press, pp. 1-25.

Guelman, A.; Cabaluz, F. y Salazar, M.(Coords.) (2018). Educación Popular y Pedagogías Críticas en América Latina y el Caribe: corrientes emancipatorias para la educación pública del Siglo XXI Buenos 
Aires:

Clacso.

Disponible

en

http://biblioteca.clacso.edu.ar/clacso/se/20181113022418/Educacion_popular.pdf

(Consultado 3-2-2020).

Guerreiro, S. (2013). Teachers' Pedagogical Knowledge and the Teaching Profession Background. Report and

Project Objectives. Paris: OCDE. Disponible en

http://www.oecd.org/education/ceri/Background document to Symposium ITEL-

FINAL.pdf (Consultado 3-2-2020).

Henz, H. (1976). Tratado de Pedagogía Sistemática. Barcelona: Herder, 2ª ed.

Herbart, J. F. (1806). Pedagogía General derivada del fin de la educación. Madrid: La lectura, s. f.

Hirst, P. H. (1966). Educational Theory, en J. W. Tibble (Ed.), The Study of Education. Londres: Routledge and Kegan Paul, pp. 29-58.

Hirst, P. H. (1967). Philosophy and Educational Theory, en I. Scheffler (Ed.), Philosophy and Education. Modern Readings. Boston: Allyn and Bacon, pp. 78-95.

Hirst, P. H. (1973). The Nature and Scope of Educational Theory, en G. Langford y D. J. O'connor (Eds.), New Essays in the Philosophy of Education. Londres: Routledge and Kegan Paul, pp. 6675.

Hirst, P. H. (1974). Knowledge and the Curriculum. A Collection of Philosophical Pappers. Londres: Routledge and Kegan Paul.

Hubert, R. (1975). Tratado de Pedagogía Ceneral. Buenos Aires: El Ateneo, $7^{\mathrm{a}}$ ed.

Ibañez-Martín, J. A. (1982). La formación pedagógica del profesorado y el plural concepto de Filosofía de la Educaci6n. Revista Española de Pedagogía, 40 (158), 61-71.

Ibáñez Martín, J. A. (2005). Anámnesis y prognosis de la Filosofía de la educación, en J. Ruiz Berrio (Ed.), Pedagogía y educación ante el siglo XXI. Madrid: Universidad Complutense, pp. 85-103.

Ibáñez Martín, J. A. (2009). Asentamiento y futuro de la Filosofía de la Educación en España, en Actas del VI Congreso Internacional de Filosofía de la Educación. Madrid: Dykinson, pp.127-135.

Jover, G. y Thoilliez, B. (2010). Cuatro décadas de Teoría de la educación: ¿una ecuación imposible? Teoría de la Educación. Revista Interuniversitaria, 22 (1-2010), 43-64.

Kant, I. (2003). Pedagogía. Madrid: Akal, 3ํe․ (Edición original, 1803).

Kroman, N. (1977). Epistemology as the Focus of Teacher Competence. The Journal of Educational Thought, 11 (2), 119-129.

Ladriére, J. (1977). El reto de la racionalidad. Salamanca: Sígueme.

Lakatos, I. y Musgrave, A. (1981). Matemáticas, ciencia y epistemología. Madrid: Alianza Universidad.

Lucas, Ch. J. (Ed.) (1969). What is Philosophy of Education? Toronto: Collier-MacMillan.

Luque, D. (2019). Desarrollos interpretativos de la filosofía de la educación en la tradición anglófona: un intento de sistematización. Revista Española de Pedagogía, 77 (272), 67-82.

Marín Ibáñez, R. (1983). Medio siglo de Pedagogía General. Revista Española de Pedagogía, 41 (159), 9-23.

Martínez, M. y otros (2016). La Educación, en teoría. Madrid: Síntesis.

Medina Rubio, R. (1992). Estatuto epistemológico de la Teoría de la educación, en R. Medina y otros, Teoría de la Educación. Madrid: Uned, pp. 213-232.

Mialaret, G. (1972). Introducción a la pedagogía. Barcelona: Planeta.

Mialaret, G. (1977). Las ciencias de la educación. Barcelona: Oikos-Tau.

Moore, P. W. (1980). Introducción a la teoría de la educación. Madrid: Alianza. (1974, 1ª ed.). 
Morín, E. (2000). Los siete saberes necesarios a la educación del futuro. Venezuela: UNESCO- IESALC. Universidad Central de Venezuela.

Morin, L. (1975). Los charlatanes de la nueva Pedagogía. Perplejidades de un joven profesor. Barcelona: Herder.

Nassif, R. (1975). Pedagogía general. Madrid: Cincel, 2ª ed. (1ª edición en Buenos Aires, 1958).

Nassif. R. (1985). Teoría de la educación. Problemática pedagógica contemporánea. Madrid: Cincel, 3ạ ed.

Naval, C. (2008). Teoría de la educación. Un análisis epistemológico. Pamplona: EUNSA.

Naval, C. y Altarejos, F. (2000). Filosofía de la educación. Pamplona: EUNSA.

Nohl, H. (1968). Teoría de la educación. Buenos Aires: Losada, $5^{\underline{a}}$ ed. (Fecha edición alemana de 1935).

Nordembo, S. (1979). Philosophy of Education in the Western World. Developmental Trends during the Last 25 Years. International Review of Education, 25 (2-3), 435-459.

Novak, J. (1977). A Theory of Education. Ithaca, NY: Cornell University Press. (Versión en castellano. Teoría y práctica de la educación. Madrid: Alianza Universidad. 1988).

O'Connor, D. J. (1971). Introducción a la filosofía de la educación. Buenos Aires: Paidós.

O'Connor, D. J. (1973). The Nature and Scope of Educational Theory, en G. Langford y D. J. O'connor (Eds.), New Essays in the Philosophy of Education. Londres: Routledge and Kegan Paul, p.47-65.

Ortega y Gasset, J. (1976). Ideas y creencias. Madrid: Espasa-Calpe, Austral, 8 aed.

Ortega, P. (2003). (Coord.). Teoría de la educación, ayer y hoy. Seminario Interuniversitario de Teoría de la Educación. Murcia: Selegráfica.

Peters, R. S. (1969). El concepto de educación. Buenos Aires: Paidós.

Peters, R. S. (1977). Filosofía de la educación. México: Fondo de Cultura Económica.

Popper, K. R. (1984). El universo abierto. Madrid: Tecnos.

Popper, K. R. y Eccles, J. C. (1980). El yo y su cerebro. Barcelona: Labor.

Puig, J. M. a (1986). Teoría de la educación. Una aproximación sistémico-cibernética. Barcelona: PPU

Puig, J. M.a (2003). Prácticas morales. Una aproximación a la educación moral. Barcelona: Paidós.

Putnam, H. (1962). What Theories Are Not?, en E. Nagel, P. Suppes y A. Tarski (Eds.), Logic, Methodology and Philosophy of Science. (Proceedings of the 1960 International Congress of Logic, Methodology and Philosophy of Science). Stanford: Stanford University Press, pp. 240-254.

Quintana, J. M.. (1982). Concepto de filosofía de la educación. Revista Española de Pedagogía. 40 (157), 65-74.

Quintana, J. M. (1988). Teoría de la Educación. Concepción antinómica de la educación. Madrid: Dykinson.

Quintana, J. M.a (2009). La sabiduría en la orientación cosmovisional de las personas, en J. A. IbáñezMartín (Coord.), Educación, conocimiento y justicia. Madrid: Dykinson, pp. 215-234.

Quintanilla, M. A. (1978). El estatuto epistemológico de las ciencias de la educación, en A. Escolano y otros, Epistemología y educación. Salamanca: Sígueme, pp. 92-118.

Rabazas, T. (Coord.) (2014). El conocimiento teórico de la educación en España. Evolución y consolidación. Madrid: Síntesis.

Rodríguez, A. (2006). Conocimiento de la educación como marco de interpretación de a Teoría de la Educación como disciplina. Tendencias pedagógicas, (11), 31-53.

Romero, C. (2006). Conocimiento, acción y racionalidad en educación. Madrid: Biblioteca Nueva.

Sáez, R. (2007). La teoría de la educación, una búsqueda sin término en la construcción del conocimiento de la educación. Encounters on Education, (8, fall), 109-126. 
Sáez, R. (2016). Teoría de la Educación: conocimiento de la educación, investigación, disciplina académica, en J. M. Touriñán y S. Longueira (Coords.), Pedagogía y construcción de ámbitos de educación. La función de educar. Colombia, Cali: Redipe, pp. 123-152.

Sarramona, J. (2007). El futuro de la teoría de la educación en perspectiva tecnológica, en J. Boavida y A. García del Dujo (Eds.), Teoría da Educaçao. Contributos Ibéricos. Coimbra: Imprenta da Universidades de Coimbra, pp. 593-608.

Sección de Ciencias de la Educación (1984). Cíncuentenario de los estudios universitarios de Pedagogía. Madrid: Universidad Complutense de Madrid, Facultad de Filosofía y Ciencias de la Educación.

SI(e)TE. Educación (2013). Crítica y desmitificación de la educación actual. Barcelona: Octaedro.

SI(e)TE. Educación (2016). Repensar las ideas dominantes en la educación. Santiago de Compostela: Andavira.

SI(e)TE. Educación (2018). La Pedagogía, hoy. Santiago de Compostela: Andavira.

SI(e)TE. Educación (2020). Saber para hacer en educación. Santiago de Compostela: Andavira.

Smeyers, P. (2010). Repensar la filosofía de la educación. Teoría de la Educación. Revista Interuniversitaria, 22 (1), 117-140.

Suchodolsky, B. (1979). Philosophy and Education. International Review of Education, 25 (2-3) 347-366.

Suppe, F. (Ed.) (1979). La estructura de las teorías científicas. Madrid: Editorial Nacional.

Tibble, J.W. (1969). The Study of Education. Londres: Routledge and Kegan Paul.

Toulmin, S. (1977). La comprensión humana. El uso colectivo y la evolución de los conceptos. Madrid: Alianza editorial. (edición inglesa de 1972, Human Understanding. The Collective Use and Evolution of Concepts. Princeton University Press).

Toulmin, S. (2003). Regreso a la razón. Barcelona: Península.

Toulmin, S.; Rieke, R. y Janik, A. (1979). Introduction to Reasoning. Londres: Collier-MacMillan.

Touriñán, J. M. (1979). El sentido de la libertad en la Educación. Madrid: Magisterio Español.

Touriñán, J. M. (1987). Teoría de la Educación. La educación como objeto de conocimiento. Madrid: Anaya.

Touriñán, J. M. (1989). Teoría de la Educación. Identificación de la asignatura y competencia disciplinar. Revista de Ciencias de la Educación 35 (137), 7-35.

Touriñán, J. M. (1990a). El conocimiento pedagógico. Corrientes y parámetros. Educar, (14-15), 81-92.

Touriñán, J. M. (1990b). Profesionalización como principio del sistema educativo y función pedagógica. Revista de Ciencias de la Educación, 36 (141), 9-23.

Touriñán, J. M. (1995). Exigencias de la profesionalización como principio del sistema educativo. Revista de Ciencias de la Educación, (164), 411-437.

Touriñán, J. M. (2008). Teoría de la Educación: investigación disciplinar y retos epistemológicos. Magis. Revista Internacional de Investigación en Educación, 1 (1), 175-194.

Touriñán, J. M. (2012a). Racionalidad administrativa y racionalidad epistemológica. Una convergencia necesaria en la universidad actual, en M. Agís, C. Baliñas y J. L. Pastoriza (Coords.), A Universidade. Raíces históricas e desafíos de futuro. Santiago de Compostela: Xunta de Galicia-Sociedad interuniversitaria de Filosofía, pp. 287-306.

Touriñán, J. M. (2012b). La construcción de ámbitos de educación. Una aproximación a la relación entre áreas de experiencia cultural y educación desde la mirada pedagógica, en Actas del Congreso internacional REDICIS Cultura, educación e innovación. Santiago de Compostela, 
septiembre, 2012 (publicado en 2014, "Cultura, educación e innovación". Santiago de Compostela: Grupo Correo Gallego, pp. 317-338).

Touriñán, J. M. (2013). Conocer, enseñar y educar no significan lo mismo. El carácter y el sentido de la educación como referentes de su significado desde la mirada pedagógica. Teoría de la educación. Revista Interuniversitaria, 25 (1), 25-46.

Touriñán, J. M. (2014). Dónde está la educación. Actividad común interna y elementos estructurales de la intervención. A Coruña: Netbiblo.

Touriñán, J. M. (2015a). Pedagogía mesoaxiológica y concepto de educación. Santiago de Compostela: Andavira (Disponible $2^{\mathrm{a}}$ edición de 2016).

Touriñán, J. M. (2015b). La complementariedad metodológica: Principios de investigación pedagógica. Hermes Analógica, (6), 6-43.

Touriñán, J. M. (2016). Pedagogía general. Principios de educación y principios de intervención. A Coruña: Bello y Martínez.

Touriñán, J. M. (2017). Mentalidad pedagógica y diseño educativo. De la pedagogía general a las pedagogías aplicadas en la función de educar. Santiago de Compostela: Andavira.

Touriñán, J. M. (2018a). Concepto de educación y conocimiento de la educación. The Concept of Education and the Knowledge of Education. Colombia-Nueva York: Redipe (Bowker-Books).

Touriñán, J. M. (2018b). La significación del conocimiento de la educación y su capacidad de resolución de problemas: fundamentos desde el conocimiento pedagógico. Revista Boletín Redipe, 7 (1), enero, 25-61.

Touriñán, J. M. (2018c). Imagen social de la Pedagogía, en Grupo SI(e)TE. Educación, La pedagogía, hoy. Santiago de Compostela: Andavira, cap. 5.

Touriñán, J. M. (2018d). El lenguaje de la educación; más allá de lemas y metáforas. Revista Boletín Redipe, 7 (10), octubre, 31-58.

Touriñán, J. M. (2019a). La Pedagogía no es la Filosofía y la Filosofía no es la Filosofía de la Educación. Revista Boletín Redipe, 8 (5), mayo, 17-84.

Touriñán, J. M. (2019b). ¿Qué estamos haciendo mal? Una reflexión desde la Pedagogía, en A. de la Herrán, J. M. Valle y J. L. Villena (Coords.), ¿Qué estamos haciendo mal en la educación? Reflexiones pedagógicas para la investigación, la enseñanza y la formación. Barcelona: Octaedro, pp. 287-330.

Touriñán, J. M. (2019c). La transferencia de conocimiento como proceso: de la universidad al sector educativo. Una mirada desde la Pedagogía. Revista Boletín Redipe, 8 (3), 19-65.

Touriñán, J. M. (2019d). Estudiar es actividad común externa y siempre educamos con la actividad. Una aproximación desde la perspectiva mesoaxiológica. Teoría de la educación. Revista Interuniversitaria, 31 (2), 7-31.

Touriñán, J. M. (2019e). Imagen social de la Pedagogía. Competencia técnica y educación de calidad, en C. Naval, J. Vergara, A. Rodríguez y A. Bernal (Coords.), Reflexiones teóricas sobre la educación. Madrid; Dykinson, pp. 145-192.

Touriñán, J. M. (2020a). Función pedagógica, competencia técnica y transferencia de conocimiento. Colombia-Nueva York: Redipe (Bowker-Books). Libro conmemorativo del otorgamiento del I premio internacional Educa-Redipe (modalidad trayectoria profesional), bienio 2018-2019, a J. M. Touriñán López.

Touriñán, J. M. (2020b). Pedagogía de las artes. La perspectiva mesoaxiológica. Santiago de Compostela: Andavira. 
Touriñán, J. M. y Longueira, S. (Coords.) (2018). La construcción de ámbitos. Pedagogía general y aplicada. Santiago de Compostela: Andavira.

Touriñán, J. M. y Sáez, R. (2015). La mirada pedagógica. Teoría de la educación, metodología y focalizaciones. Santiago de Compostela, Andavira (Es nueva edición actualizada de la obra agotada de J. M. Touriñán, J. M. y R. Sáez, (2012). Teoría de la educación, metodología y focalizaciones. La mirada pedagógica. A Coruña: Netbiblo).

Touriñán, J. M. y Rodríguez, A. (1993a). Significación del conocimiento de la educación. Revista de Educación, (302), 165-192.

Touriñán, J. M. y Rodríguez, A. (1993b). Conocimiento de la Educación, decisiones pedagógicas y decisiones de política educativa. Teoría de la Educación. Revista Interuniversitaria, (5), 33-58.

Touriñán, J. M.; Rodríguez, A. y Longueira, S. (2019). Valores educativos comunes y específicos: análisis descriptivo de su integración pedagógica en las materias escolares a partir de la percepción de los docentes sobre su actividad. Revista Boletín Redipe, 8 (6), junio, 23-49.

Trilla, J. (1987). Teorías de la educación (bosquejo para una taxonomía). Barcelona: Universidad de Barcelona.

Tusquets, J. (1972). Teoría de la educación. Madrid: Magisterio Español.

Uljens, M. (2001) On General Education as a Discipline. Studies in Philosophy and Education, 20, 291301.

Vázquez, G. (1981). Apuntes bibliográficos de la ciencia pedagógica. Revista Española de Pedagogía, 39 (153), 9-36.

Vázquez, G. (1984). La Pedagogía General, ¿una teoría general de la educación? Problemática actual y perspectivas de futuro, en la obra conjunta, Cincuentenario de los estudios universitarios de Pedagogía. Madrid: Universidad Complutense de Madrid, pp. 13-39.

Vázquez, G. (2004). El discurrir de la Pedagogía (general) en el siglo XX: El quehacer de una reflexión sistemática sobre la acción educativa, en J. Ruiz Berrio (Ed.), Pedagogía y Educación ante el siglo XXI. Madrid: Universidad Complutense de Madrid, pp. 37-59.

Vázquez, G. (2018). La Pedagogía en el mosaico de las ciencias, en Grupo SI(e)TE. Educación, La pedagogía, hoy. Santiago de Compostela: Andavira, cap. 3.

Vega Román, E. A. (2018). ¿Pedagogía o ciencias de la educación? Una lucha epistemológica. Revista Boletín Redipe, 7 (9), 56-62.

Vera-Rojas, M. P.; Massón, R. M. ${ }^{\text {y }}$ Vera, L. A. (2018). Mirada analítica a las facultades de ciencias de la educación y la formación del profesorado. Revista Boletín Redipe, 7 (12), 207-214.

Walton, J. (1963). A Discipline of Education, en J, Walton y J. C. Kuethe (Eds.), The Discipline of Education. Madison: The University of Wisconsin Press, pp. 3-16.

Walton, J. (1971). Introduction to Education: A Substantive Discipline. Waltham, Massachussets: Xerox College Press.

Walton, J. (1974). A Confusion of Contexts. The Interdisciplinary Study of Education. Educational theory, 24 (3), 219-229.

William, D. (2008). What Should Education Research Do, and How Should It Do It? Educational Researcher, 37 (7), 432-438.

(C) 2020 by the authors. Submitted for possible open access publication under the terms and conditions of the Creative Commons Attribution (CC BY) license (http://creativecommons.org/licenses/by/4.0/). 